\title{
The effects of monetary policy on income and wealth inequality in the U.S. Exploring different channels
}

\begin{abstract}
We assess the effects of monetary policy shocks on income and wealth inequality through direct inequality measures and by analyzing several transmission channels explored in recent literature. Furthermore, we analyze two additional channels: the Housing and the Fiscal channels. The methodology adopted is a Bayesian proxy SVAR using a high-frequency identification based on the external instruments approach. Our own policy shocks are constructed for this purpose. The results show that an expansionary monetary policy shock does not have a significant effect on income inequality due to the existence of opposite channels, whereas it increases wealth inequality mainly through the portfolio channel.
\end{abstract}

Keywords: Monetary policy, Income and wealth inequality, BVAR, Proxy SVAR, High-frequency identification

JEL: E52 E58 D63 


\section{Introduction}

The recent escalation of income and wealth inequality has produced a discussion among central bankers on the potential redistributive effects of monetary policy. Cantillon (1755) in his acclaimed "Essai" published posthumously, expounded his famous "Cantillon effect" that explained how changes in the money supply lead to changes in both relative prices and the real economy, which, in turn produce evident redistributive effects. However, even though these effects have been traditionally considered as a side-effect, with the arrival of the Great Recession and unconventional measures applied by the major central banks across the world, the distributive effects of monetary policy have become one of the main concerns for both central bankers and academics.

In this paper, we provide empirical evidence of the redistributive effects of monetary policy on income and wealth inequality through the major channels identified by previous literature. In addition, as a novelty in the literature, we consider two additional channels which have not been evaluated previously, at least not in a integral way. Specifically, we use a Bayesian proxy structural vector autoregression (proxy SVAR) following Miranda-Agrippino and Ricco (2018a) to study the potential effects of expansionary monetary policy shocks on income and wealth inequality. Even though some works have applied the proxy SVAR approach to assess the distributive effects of monetary policy (Samarina and Nguyen (2019) ), the combination of the Bayesian perspective and the proxy SVAR identification has not been used in this research field. For this purpose, we also construct our own monetary policy surprises based on the works of Gertler and Karadi (2015) and Kuttner (2001). 
The seminal work by Coibion et al. (2017) identifies five channels through which monetary policy affects income and wealth distribution. First, the saving redistribution channel arises from an unexpected expansionary monetary policy that reduces the interest rate or has the effect of increasing inflation, which will benefit the real value of borrowers (normally poorer households) compared to the real value of savers (Nakajima (2015) and Doepke and Schneider (2006)). Second, the earnings heterogeneity channel appears since lower-income households are more likely to be unemployed (extensive margin) and see their wages reduced (intensive margin) if a monetary contraction occurs due to the contraction in the aggregate demand (Carpenter and Rodgers (2004); Heathcote et al. (2010) or Mumtaz and Theophilopoulou (2017)). Third, the financial segmentation channel works on the assumption that households with higher income and wealth tend to be more connected to financial markets. Hence, monetary policy-induced changes may benefit these households with better conditions (Williamson (2008) or Finer (2018)). Fourth, the income composition channel occurs when the composition of income is different across households. Hence, if an expansionary monetary policy shock boosts capital income more than labor income, and since the share of capital income is higher among the rich, this monetary policy shock would increase income inequality (Galbraith (2000) and Coibion et al. (2017)). Finally, the portfolio channel occurs when the size and composition of asset portfolios differs across households. On the assumption that higher-income households hold a greater proportion of their wealth in assets, they would benefit more from an expansionary monetary policy that increases the price of assets (Brunnermeier and Sannikov (2012); Saiki and Frost $(2014)$ or Al- 
bert et al. (2019)).

The empirical literature on the impact of monetary policy on income and wealth inequality yields mixed conclusions (see Colciago et al. (2019) for a complete survey). On the one hand, Coibion et al. (2017) show that contractionary monetary policy shocks lead to an increase in income inequality in the US, especially through the saving redistribution channel and the earnings heterogeneity channel. This outcome is found by Mumtaz and Theophilopoulou (2017) in the UK, by Furceri et al. (2017) for a panel of 32 advanced and emerging market countries and by O'Farrell et al. (2016) for the US and Canada. However, other studies show that an expansionary monetary policy would increase income and in particular wealth inequality, mainly through the portfolio channel (Domanski et al. (2016) for some countries in the Eurozone, Inui et al. (2017) and Saiki and Frost (2014) for Japan or Dolado et al. (2018) and Berisha et al. (2018) for the US).

Additionally, according to these contradictory results and to Bernanke (2015), in order to explore and quantify the full effects of monetary policy on income and wealth inequality, it is important to identify all channels through which monetary policy could have distributive effects. Taking this into account, we identify and quantify two additional transmission channels which have not been properly explored in previous literature.

First, we explore the housing channel. Although this channel has already been identified in previous literature (see Domanski et al. 2016) or Colciago et al. (2019)), it has not been fully explored. More specifically, the empirical literature has analysed the distributional effects of monetary policy on wealth through increases in house prices (see Lenza and Slacalek (2018)). However, 
this work also assesses the fact that monetary policy could imply changes in rent prices and, therefore, imply distributive effects on income as well. On the one hand, as evidenced by the conventional literature, expansionary monetary policy could increase housing prices (see Piazzesi and Schneider (2016) for a complete survey). This fact could reduce wealth inequality on the assumption that lower-income households hold a greater proportion of their wealth in housing (Wolff $(2016))$. However, on the other hand, rising housing prices may mean that some vulnerable groups, such as younger people, may face prohibitive prices when it comes to gaining access to buying a home. Moreover, this fact could increase rental incomes and benefit higherincome households who earn proportionally more of their income in this way (Bonnet et al. (2014)) and, hence, increase income inequality. Additionally, we should take into account that for low-income homeowners, the increase in housing prices could not increase the consumption and well-being of this group of households. It is explained due to the higher transaction costs these households face when they come to dispose of their properties. Furthermore, households with only one property do not benefit from higher home prices since they need a place to live. We assess and quantify the "wealth effect" and the "income effect" of the housing channel separately among different households in order to study the effects of monetary policy on income and wealth distribution through the housing channel.

Finally, as a novelty in the literature, we add the fiscal channel. The relationship between monetary and fiscal policy has gained importance in the aftermath of the financial crisis. New ways of iteration among these policies are being explored, as well as their role in determining macroeconomic out- 
comes. A great example of this is the fiscal theory of the price level (Leeper and Leith (2016) and Williamson (2008)). However, our purpose is not to explore monetary and fiscal policy jointly, but to study the fiscal effects of monetary policy and how these could affect income inequality. It is clear that the goal of the Federal Reserve is to stabilize the economy through price and unemployment targets. However, to achieve its goal, changes in monetary policy could have some implications for fiscal policy and consequently for income inequality. Dahan (1998) identifies five channels through which monetary policy could have fiscal effects. 1) Expenditure effect: if a tight monetary policy leads to a reduction in output and employment, the government can choose to cushion this effect caused by monetary policy through implementing a more aggressive fiscal policy (increasing government spending or reducing taxes). 2) Revenue effect: if a tight monetary policy drives down output and employment, taxes and other government revenues could be reduced which, in turn, would increase the government budget deficit. Moreover, this deficit could be higher as a consequence of automatic stabilizers. The final decision of the government to adjust budget deficit via discretional fiscal policy, or not, will determine the final effect of this channel. 3) Debt effect: assuming sticky prices, if a tight monetary policy results in a higher short-term interest rate and, as a consequence, a higher long-term interest rate, this could increase the debt servicing for interest and increase the budget deficit with a higher interest rate. This is true not only when the Fed changes interest rates by using conventional monetary policy, but also when it changes rates using unconventional monetary policy such as large-scale asset purchase operations, via an effect on risk premium Gagnon 
(2010) . 4) Seigniorage effect: if a tight monetary policy reduces revenues for seigniorage, which are usually transferred to the government, this would have implications for the public budget and for fiscal decisions Carpenter et al. (2015). 5) Price effect: a lower rate of inflation as a consequence of a tight monetary policy can lead to a lower rate of erosion of the nominal interest payments and a higher real value of public debt, changing the path of fiscal consolidation Sims (2013). According to these channels, it seems plausible that monetary policy could have implications for fiscal policy decisions and, consequently, this could have distributive effects. However, the manifestation of these effects on income inequality depends on the many factors that are exogenous decisions of policy makers. For example, the savings in the payment of interest on the debt caused by an expansionary monetary policy could be destined to social programs that reduce inequality or to a decrease in taxes with less clear distributional effects. Therefore, even if monetary policy had fiscal effects, these effects on inequality would not be evident.

Empirically, using direct measures of inequality, our results suggest that an expansionary monetary policy shock increases wealth inequality mainly driven by the portfolio channel. However, we do not find statistical significance when we assess the final effect of the monetary policy shock on income inequality. A plausible explanation is due to the existence of opposing channels. More specifically, we find that saving redistribution, earnings heterogeneity as well as fiscal and housing channels could reduce income inequality following an expansionary monetary policy, whereas the income composition channel would work in the opposite direction making the final effect of monetary policy on income inequality ambiguous. 
The paper is structured as follows. Section 2 describes the empirical model used and the identification strategy. In section 3, we present the empirical results on income and wealth inequality measures and the transmissions channels. Section 4 concludes.

\section{Methodology}

\subsection{The model}

The methodology adopted is Bayesian proxy structural vector autoregression (Bayesian proxy SVAR). This technique is the result of estimating impulse response functions (IRFs) by combining identification with external instruments and Bayesian methods in a vector autoregression setting. Let $Y_{t}$ be the vector of variables of interest to be explained. The structural form of the VAR representation can be represented as

$$
A Y_{t}=C+\sum_{j=1}^{p} B_{j} Y_{t-j}+\varepsilon_{t}
$$

where $\mathrm{A}$ is a nxn matrix representing the contemporaneous relationship between the endogenous variables and $n$ denotes the length of the endogenous variables, $Y_{t}$ is a nx1 vector that contains the baseline variables in the baseline, $\mathrm{C}$ is a $\mathrm{nx} 1$ vector of constant terms, $B_{j}$ is a nxn matrix that captures the coefficients associated with each lagged variable and $\varepsilon_{t}$ is a nx1 vector denoting the structural error terms.

Given the potential problem of identification due to the endogenous variables, we cannot uniquely identify the structural relationships between the variables included in $Y_{t}$. For this reason, we estimate the reduced form VAR in order to recover the structural parameters of interest afterwards. 
The reduced form representation to be estimated is given by

$$
Y_{t}=c+\sum_{j=1}^{p} \Phi_{j} Y_{t-j}+u_{t}
$$

where $c=A^{-1} C ; \Phi_{j}=A^{-1} B_{j}$ and $u_{t}=A^{-1} \varepsilon_{t}$.

The nx1 vector $u_{t}$ represents the reduced form residuals with $\operatorname{Var}\left(u_{t}\right)=$ $\Sigma, u_{t}$ follows a normal distribution with mean 0 and variance $\Sigma$, i.e., $u_{t} \sim$ $N(0, \Sigma)$. We set the lag length to twelve based on the Aikaike's information criterion (AIC) and the reduced form model is estimated at monthly frequency from 1982M1 to 2014M12.

The variables included in the baseline specification are 


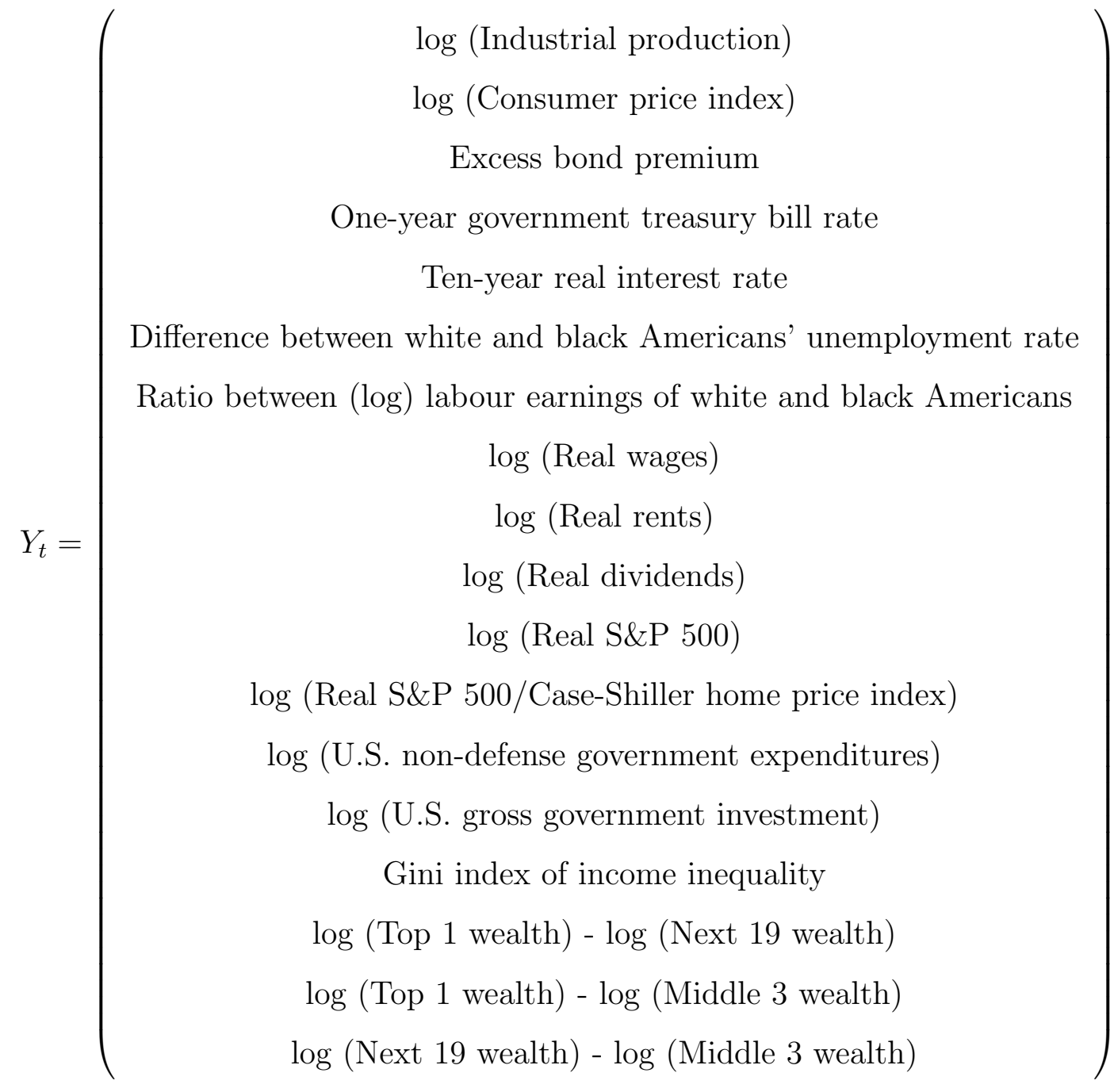

The first four variable: 1 capture measures of real economic activity, prices,

\footnotetext{
${ }^{1}$ The responses of Industrial production, the consumer price index and excess bond premium in the baseline are consistent with macroeconomic theory. Furthermore, these results are also obtained by Gertler and Karadi (2015) and Miranda-Agrippino and Ricco (2018b). The IRFs for these activity, price and financial variables are shown in figure A.6 in Appendix A.
} 
as well as financial and interest rate conditions. We use the one-year government treasury bill rate (GS1) as the policy indicator, which indicates the stance of monetary policy. This longer-term rate is a more proper policy indicator -as opposed to federal funds- for assessing the response of interest rates to monetary policy shocks. Following Gertler and Karadi (2015), government bond rates are useful since their innovations also contain information about forward guidance, i.e., changes in expectations about the future path of monetary policy and yields at longer horizons.

Moreover, we consider the following variables $2^{2}$ as representatives of each inequality transmission channel and direct measures of income and wealth inequality. For the saving redistribution channel, the ten-year real interest rate is used as benchmark. According to the earnings heterogeneity channel, we use the difference in unemployment rates between white Americans and black African American workers and the ratio of labour earnings to the same racial groups for the extensive margin and the intensive margin respectively. Real wages and real dividends are considered for the income composition channel. In order to evaluate the portfolio channel, the real S\&P 500 price index stock is used as representative of this channel. According to the two additional channels, we consider the real S\&P/Case-Shiller national home price and real rents for the housing channel. For the fiscal channel, the U.S. non-defense government expenditures and the U.S. gross government investment are considered as measures of the fiscal policy. Finally, for the direct inequality measures we use the Gini index of income inequality and we con-

\footnotetext{
${ }^{2}$ The detailed explanation of the construction of the variables considered is explained in appendix B.
} 
struct the differences between percentile groups of the cross-sectional wealth distribution of log levels as measures of wealth inequality by considering three percentile groups: the Top 1\%, the Next $19 \%$ and the Middle 3 quintiles. The construction of these variables are carefully explained in Appendix B.

Given the large set of variables in the baseline, we adopt a Bayesian perspective in order to deal with the curse of dimensionality induced by the structure of the model. We follow the algorithm of Miranda-Agrippino and Ricco (2018a) where a standard Normal-Inverse Wishart (NIW) conjugate priors is assumed as prior distributions for $(\Phi, \Sigma)$. Therefore, a multivariate normal distribution is assumed for the regression coefficients, and an Inverse Wishart specification for the covariance matrix of the error term. This assumption is chosen so that prior expectations and variances of $\Phi$ coincide with the so called 'Minnesota' prior proposed originally by Litterman (1986).

\subsection{Identification}

Before explaining the identification of monetary policy surprises, it is worth mentioning that the definition of a monetary policy surprise is not easy to define, specifically after the multidimensional policy actions carried out during the Great Recession period. We follow Gerko and Rey (2017) denoting a monetary policy shock $2^{3}$ as an unanticipated movement in the current monetary policy stance or about changes in future policy expectations.

The identification strategy used to recover the structural parameters of interest in equation 1 is the external instruments or proxy SVAR approach based on the works of Gertler and Karadi (2015), Mertens and Ravn (2013)

\footnotetext{
${ }^{3}$ We also consider as robustness test the different factors of Swanson (2015) as proxies for different monetary policy actions during the zero lower bound period.
} 
and Stock and Watson (2012). The basic idea under this identification strategy is to exploit the information of a variable not included in the model (instrument) that contains information in monetary surprises.

Under this scenario, either the Cholesky decomposition or sign restriction may not be adequate for estimating the impulse response functions to a monetary policy shock. Cholesky factorization imposes the matrix A to be a lower triangular matrix meaning that the variables ordered earlier do not react to a shock of the variables ordered later. Therefore, the order of the VAR specification does matter and we may obtain unstable and sensitive responses depending on the order position of the variable reflecting the monetary policy stance. In addition, the Cholesky scheme may lead to price and activity puzzles (see also Gertler and Karadi (2015) and Miranda-Agrippino (2016)). Furthermore, given that the effect of monetary policy is a priori ambiguous because of the number of channels through which these actions affect agents (see Coibion et al. (2017)), the adoption of sign restrictions may provide misleading results for the responses on income and wealth inequality.

Due to the fact that we are only interested in the responses to a monetary policy shock, it is sufficient to identify only the shock associated with the policy indicator, i.e, the one-year government treasury bill rate. Therefore, to obtain the responses to a monetary policy shock, we need to estimate equation

$$
Y_{t}=c^{m p}+\sum_{j=1}^{p} \theta_{j} Y_{t-j}+a \varepsilon_{t}^{m p}
$$

given that $u_{t}=A^{-1} \epsilon_{t} . c^{m p} \in c$ represents the constant term associated to the monetary policy equation. $a$ denotes the unknown column of matrix 
$A^{-1}$ that represents the responses to the associated monetary policy shock.

Thus, we can represent the structural form representation of the variables not associated with monetary policy as

$$
Y_{t}=c^{i}+\sum_{j=1}^{p} \theta_{j} Y_{t-j}+a \varepsilon_{t}^{i} \quad \forall i \neq m p
$$

Assuming this partition, the structural shocks contained in $\varepsilon_{t}$ can also be expressed as $\varepsilon_{t}=\left[\varepsilon_{t}^{m p} \varepsilon_{t}^{r^{\prime}}\right]^{\prime}$ where $\varepsilon_{t}^{r^{\prime}}$ represents all the structural shocks in equation 4. Thus, $\varepsilon_{t}^{m p}$ represents the structural shock associated with the policy indicator and $\varepsilon_{t}^{r}$ represents the structural shock associated with all other endogenous variables at period t. Note that the reduced form residuals are a linear combination of the structural shocks $\epsilon_{t}$ through the inverse 4 of vector A. Hence, the reduced VAR innovations $u_{t}$ can be represented as a partition of $u_{t}=\left[u_{t}^{m p} u_{t}^{r_{\prime}}\right]^{\prime}$, where $u_{t}^{r_{\prime}}$ contains all the reduced-form residuals but the one associated to monetary policy. Hence, $u_{t}^{m p}$ represents the reduced form residual associated with the policy indicator and $u_{t}^{r}$ denotes the reduced form residual associated with all other variables included in $Y_{t}$. For a more detailed and technical description of how to obtain IRFs, see Gertler and Karadi (2015)

Under this condition, having an external instrument that satisfies the following conditions is required

$$
E\left(Z_{t} \varepsilon_{t}^{m p}\right)=\phi
$$

\footnotetext{
${ }^{4}$ In order to satisfy this condition, we have to assume invertibility. If this assumption does not hold, the structural parameters of interest cannot be recovered.
} 


$$
E\left(Z_{t} \varepsilon_{t}^{r}\right)=0
$$

where $\phi \neq 0$. These are the traditional assumptions required for obtaining an instrument for $\varepsilon_{t}^{m p}$.The first assumption is the relevance condition ${ }^{5}$ that implies that the set of instruments has to be correlated with the structural shock of the policy indicator. The second assumption is the exogeneity condition meaning that the set of instruments has to be uncorrelated with the structural shocks associated with the remaining endogenous variables in $Y_{t}$. This condition is essential in order to solve the problem of identification that we face. The typical challenge of the instrumental variable approach is to satisfy the exogeneity condition since it cannot be tested.

The current month's federal fund future (FF1) is used as instrument to identify the policy shocks. According to Ramey (2016), this future contract measures how the market changes its expectations about the Fed Funds rate in the current month from the current date given the new information received by the Federal Open Market Committee (FOMC). Furthermore, financial futures data are ideal for ensuring that a shock is unanticipated. Moreover, the availability of intradaily frequency of future contracts allow to consider changes in future contracts in a tight window around FOMC meetings as monetary surprises. By having a time restriction, the variation of the FF1 will most likely due to monetary policy decisions (see Gürkaynak et al. (2005) and Nakamura and Steinsson (2018)). Thus, the FF1 instrument is likely to satisfy the exogeneity assumption.

\footnotetext{
${ }^{5}$ Results of the F-statistic in the first-stage regression for each specification is provided in table C.2 in Appendix C.
} 
We construct our own shocks on the basis of the methodology proposed by Kuttner (2001), Gürkaynak et al. (2005) and Nakamura and Steinsson (2018). The basic idea of this approach is to identify the surprise component due to a monetary policy announcement by means of the change in first-differences in the federal fund rate around the FOMC dates. The time-frame considered to identify these surprises was a tight window of 30-minutes, which begins 10 minutes before the monetary policy announcement up until 20 minutes after the monetary policy release. Over the period analyzed, specifically, from July 1979 to February 2018, we use the shocks provided by Gertler and Karadi (2015) up to July 2012 and from July 2012 to February 2018 we built our own shocks where 46 additional monetary policy meetings took place.

Due to the structure of the federal fund futures, its payoff is calculated by the average effective federal funds rate that has prevailed over the calendar month specified in the contract. For this reason, it is necessary to apply a scale factor. Hence, the monetary surprise at each FOMC meeting is calculated as

$$
m p 1_{t}=\left(F F 1_{t}-F F 1_{t-\Delta t}\right) \frac{D}{D-d}
$$

where we denote $m p 1_{t}$ as the surprise component due to a monetary policy announcement. $t-\Delta t$ represents the time immediately before the FOMC commitment, $d$ is the day of the FOMC commitment and $D$ are the days of the month on which the FOMC commitments take place. 


\section{Results}

For ease of exposition, we split the results of the baseline into two subsections as follows. First, the impulse responses of the income and wealth inequality measures are shown in figure 1. Second, the responses of the potential channels through which monetary policy operate are displayed in figure 4 .

\subsection{Results of monetary policy on income and wealth inequality}

The estimated responses of the direct measures of income and wealth inequality are shown in figure 1. According to the responses for the Gini index of income inequality (Gini Income), an expansionary monetary policy shock of 20 basis points has no statistically significant response in all the horizons considered. The absence of statistical significance in terms of income inequality is in line with the recent literature that does not show a common pattern regarding the effects of monetary policy on income distribution (see Colciago et al. (2019) for a complete survey). In this vein, several studies suggest that conventional monetary tightening could increase income inequality (Coibion et al. 2017) for the U.S., Mumtaz and Theophilopoulou (2017) for U.K. and Samarina and Nguyen (2019) for the Euro Area. However, recent studies focusing on the distributional effects of unconventional monetary policy show that expansionary monetary policy also could increase income inequality (Berisha et al. (2018) for the U.S., Inui et al. (2017) and Saiki and Frost (2014) for Japan and El Herradi and Leroy (2019) for a set of 12 advanced economies.

To evaluate the effects of monetary policy on wealth inequality, we con- 
sider differences between different percentile groups of the cross-sectional distribution of log levels. In particular we consider three percentile groups: the Top 1\%, the Next 19\% and the Middle 3 quintiles. As can be observed, expansionary monetary policy increases the differences in the wealth distribution, suggesting that loosening monetary policy increases wealth inequality. In particular, a one standard deviation monetary policy shock has a statistically significant positive impact on wealth inequality up to 5 months after the shock approximately. In all cases, the responses of the differences are positive, showing that upper shares benefit more than lower shares from the expansionary shock of monetary policy. These results are in line with recent literature which point out that expansionary monetary policy could increase wealth inequality mainly driven by its effect on stock prices (see Albert and Gómez-Fernández (2018) for the U.S., Saiki and Frost (2014) for Japan and Domanski et al. (2016) for a set of developed economies). 
Figure 1: Inequality measures for the baseline
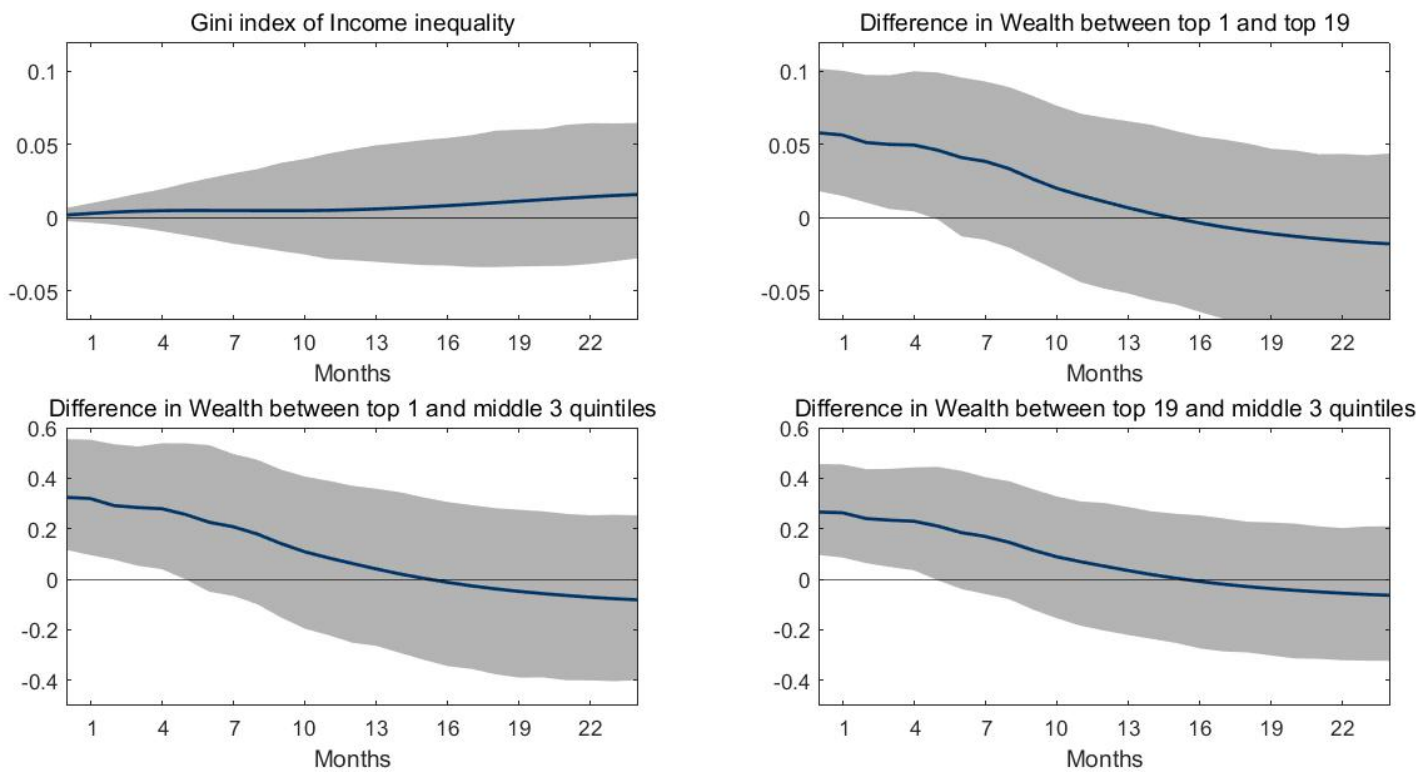

Note: IRFs to a 20 basis point decrease in the one-year government treasury bill for the direct measures of income and wealth inequality from the baseline. Sample: 1982M1:2014M2. Shaded regions represent 90\% posterior confidence bands.

To check the validity of the results, alternative measures of economic inequality are considered. First, the Gini index of wealth inequality is considered. We replace the wealth inequality measures in the baseline by the Gini index. The resulting IRFs in Figure 2 display the results on income and wealth inequality. Regarding income inequality, we still obtain a nonstatistically significant response to a 20 basis point expansionary monetary policy shock. Results on wealth inequality shows a positive statistically significant response implying an increase in wealth inequality. 
Figure 2: Gini indexes of income and wealth inequality
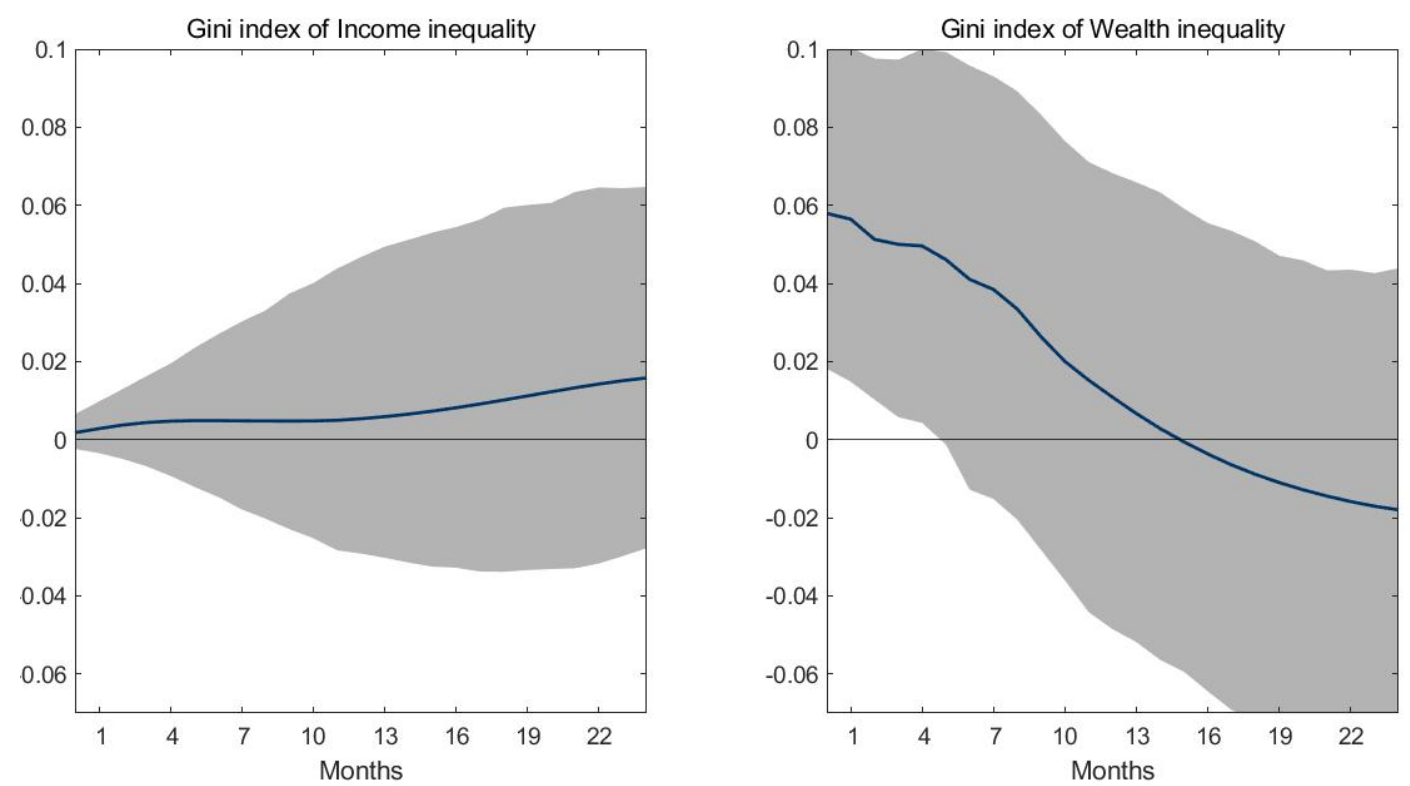

Note: IRFs to a 20 basis point decrease in the one-year government treasury bill for the Gini indexes of income and wealth inequality. Sample: 1982M1:2014M2. Shaded regions represent $90 \%$ posterior confidence bands.

Moreover, we consider the Gini index of pre-tax income and post-tax income constructed by Coibion et al. (2017). Figure 3 shows the responses on income and wealth inequality. As can be observed, the responses on wealth inequality are still the same as in the baseline. In addition, the responses after an expansionary monetary policy shock on the new measures of income inequality are not significant. Thus, we can conclude that the results are robust to the consideration of alternative inequality measures. 
Figure 3: Gini indexes of pre-tax and post-tax income inequality
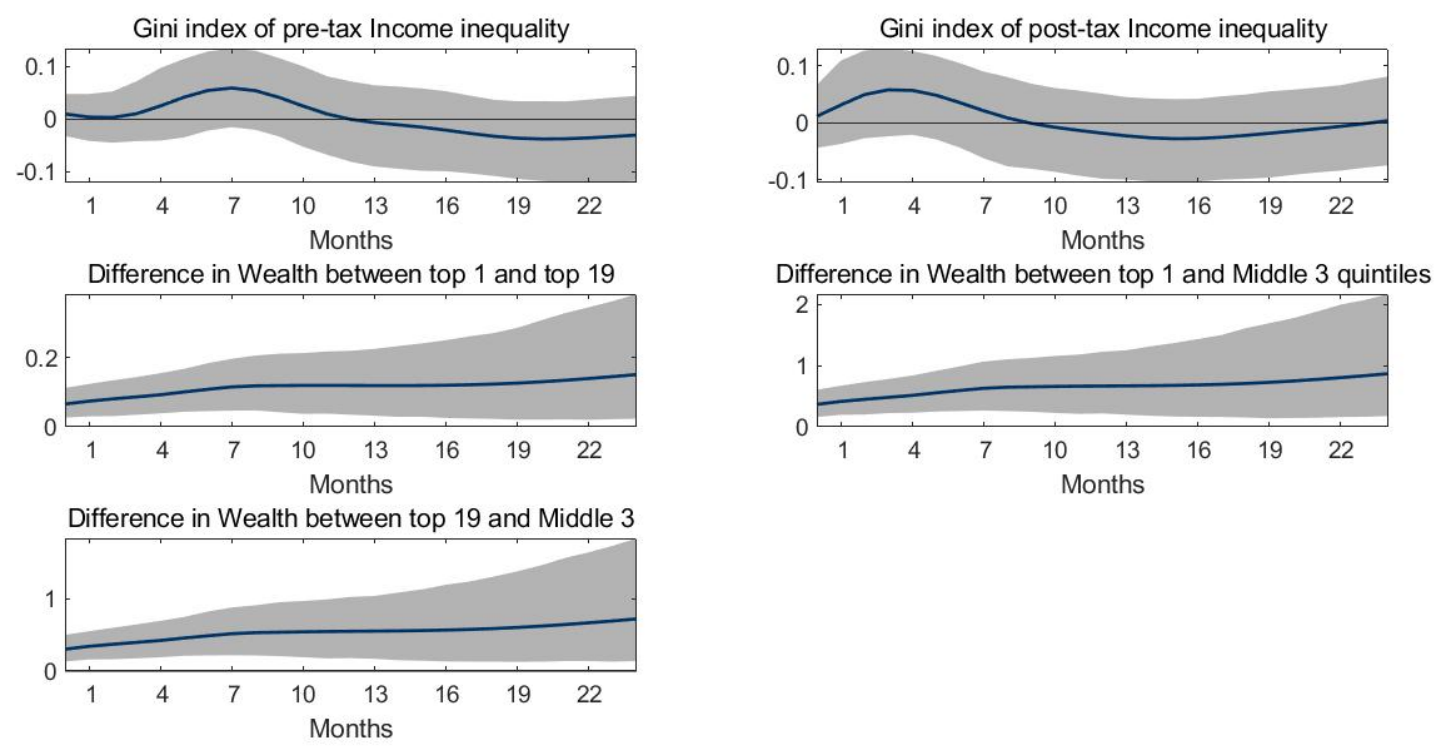

Note: IRFs to a 20 basis point decrease in the one-year government treasury bill for the Gini indexes of pre-tax and post-tax income inequality. Sample: 1982M1:2014M2. Shaded regions represent 90\% posterior confidence bands.

\subsection{Results of transmission channels}

The empirical evidence in section 3.1 suggests that expansionary monetary policy does not affect income inequality but does increase wealth disparity. Given these results, it is crucial to assess the effect of monetary policy on the potential transmission channels that affect the distribution of income and wealth in order to accurately understand the distributional effects of monetary policy. However, it is important to emphasize that this part is only qualitative and suggestive and does not offer a quantification of the relevance of the different channels. Still, it may be a relevant analysis to know the direction and sign of these channels. Figure 4 shows the IRFs of the inequality transmission channels identified by Coibion et al. (2017) and the 
two additional channels we identify.

First, to explore the saving redistribution channel, we evaluate the tenyear real interest rate. According to the standard theory, we show that real interest rate is statically reduced after an expansive monetary shock, although only for the first month after the shock. A similar result is also observed, for example, by Gertler and Karadi (2015). Hence, according to the assumption that a reduction in real interest rates will hurt savers and benefit borrowers (Nakajima (2015); Doepke and Schneider (2006)) since lenders belong to the higher-income households and borrowers to the lowerincome households, this channel would tend to reduce income inequality.

To analyse the earnings heterogeneity channel, we use two indicators of this channel. First, to assess the extensive margin, that is the job creation, we use the difference in unemployment rates between white Americans and black African American workers as an indicator. Unfortunately, we do not have labor data for the different groups of household incomes, but we rely on the plausible assumption that blacks are usually located in the bottom part of the income and wealth distribution (this assumption has been shown for instance by Wolff (2016) or Kuhn et al. (2019)). Hence, a monetary shock which reduces this difference among these unemployment rates, would reduce income inequality (Blanchard (1995)). The result of this indicator shows that the expansionary monetary policy shock reduces the gap between these two unemployment rates, although the response of this variable is only slightly significant since the month fourth to seventh following the shock. As predicted by Blanchard (1995) and empirically shown by Carpenter and Rodgers (2004), we find that an expansionary monetary policy shock bene- 
fits more racial minorities, reducing the gap in unemployment rates among both racial groups. Hence, under the assumption that racial minorities are in the bottom part of income distribution, the expansionary shock would reduce income inequality. Second, to explore the intensive margin, that is the change in labor earnings, we use the ratio between the labor earnings of white workers and black workers as an indicator. By doing so, we do not find any statistically significant effect in this ratio. Thus, it shows that the wages of minorities are not more sensitive to monetary policy than those of whites. Therefore, the intensive margin of this channel does not seem to affect income inequality, again under the assumption that racial minorities are usually located at the lower end of the income distribution.

To evaluate the income composition channel we use real wages and dividends as indicators. Firstly, in order to analyze real wages we have used the real (log) average hourly earnings. The response of real wages to monetary policy shocks has been explored in the empirical literature, but the findings show ambiguous results. On the one hand, Keynes's general theory predicts that real wages are contra-cyclical due to the sticky-wage theory. In this scenario, as nominal wages are fixed, an aggregate demand shock moves real wages and employment in different directions. However, more recent empirical literature shows that real wages are slightly pro-cyclical. Normandin (2006) explains that the behavior and the effect of the real wage response can give an indication of the relative importance of nominal wage versus nominal price rigidities. If nominal wage stickiness is relatively more important, then real wages could fall following an expansionary monetary policy shock. By contrast, when price stickiness and limited participation restrictions are rel- 
atively more important, real wages should rise in line with output. Focusing on the responses of real wages, we find that they decrease in response to an expansionary monetary shock, being statistically significant during the first three months after the shock. These results are in line with Keynes's general theory and with other works from the U.S., such as Sims and Zha (1999); Bernanke et al. (2005) or Perry et al. (2015). This result is important for us because if an expansionary monetary policy is causing real wages to decline, this might increase short-term income inequality since the majority of a lower-income household's income derives from the job market Galbraith (2000). Secondly, we analyse the behavior of real dividends using (log) real dividends which come from the SP 500 index. In this case, as conventional theory predicts (Bernanke and Kuttner (2005)), we find that an expansionary monetary policy increases real dividends and this effect is statistically significant for up to 7 months after the shock. Hence, since higher-income households receive more income from dividends (Nakajima 2015) or Furceri et al. (2017)), this would increase income inequality . Hence, the responses of these two indicators suggest that expansionary monetary policies could increase income inequality considering the different impact and the distribution of these two different sources of income among households.

We use the (log) real price index (SP 500) stock as an indicator to assess the portfolio channel. The response of this variable shows that the reaction of the S\&P 500 is strong and statistically significant for up to 7 months after the monetary shock. Even so, the effect is quite durable and it reaches its maximum effect 1 month after the shock when the S\&P 500 increases by about 1.8 percent. According to Wolff (2016), since higher-wealth households 
hold a greater proportion of their wealth in stocks (Szymborska (2019)), they would benefit more from an expansive monetary policy that increases the price of these financial assets.

As a contribution of this paper, we also include in our model several indicators to explore the new channels described in the introduction section. With regard to the "wealth effects" of the housing channel, we use the (log) SP/Case-Shiller national home price as an indicator. We do not find a statistic significant response of this indicator. This result is also found by Kuttner (2012) who points out that the impact of interest rates on housing prices appears to be quite modest. According to these results and under the assumption that lower-wealth households hold a greater proportion of their wealth in housing (see Wolff $(2016))$, the non-effect of monetary policy on home prices would not reduce wealth inequality to compensate for the effect of the portfolio channel leading a final increase in wealth inequality as we showed in the previous subsection. On the other hand, to explore the "income effects" of the housing channel, we also estimate the price index for rent in order to analyse the response to a monetary policy shock. The response of this indicator shows that an expansionary monetary shock significantly reduces the price index for rent in the first three months after the shock. This result can seem counter-intuitive, but is also found by Duarte and Dias (2016) who provide an explanation for this price puzzle. According to these authors, in the presence of nominal or financial friction, when interest rates increase, the real cost of owning a house increases, and this increase may make some people prefer to rent instead of buying. This change in consumption behavior increases the price of rents relative to other goods. 
According to this outcome, an expansionary monetary policy could reduce income inequality on the assumption that renters are at the upper end of the income distribution (Bonnet et al. (2014)). Therefore, we conclude that the housing channel does not reduce wealth inequality by mitigating the effect produced by the portfolio channel but it could reduce income inequality through declining rents.

Finally, to explore the fiscal channel, we use two fiscal expenditures as fiscal indicators. They are U.S. non-defense public expenditures and U.S. gross public investment. The results of these two indicators show that the expansionary shock raises both indicators, reaching peaks at around $0.4 \%$ and $0.3 \%$ in non-defense public expenditure and U.S. gross public investment respectively. Hence, according to these results, we observe that monetary expansion increases fiscal expenditures as predicted by Dahan (1998) and, hypothetically, if fiscal expansion serves to finance social programs, it could reduce inequalities, although, as we pointed out in the introduction, the final effect on income and wealth inequality will depend on the decisions of policy makers. Therefore, although our results suggest that monetary expansion increases fiscal expenditures, we have no evidence to show that this necessarily reduces income inequality. 
Figure 4: Inequality transmission channels for the baseline
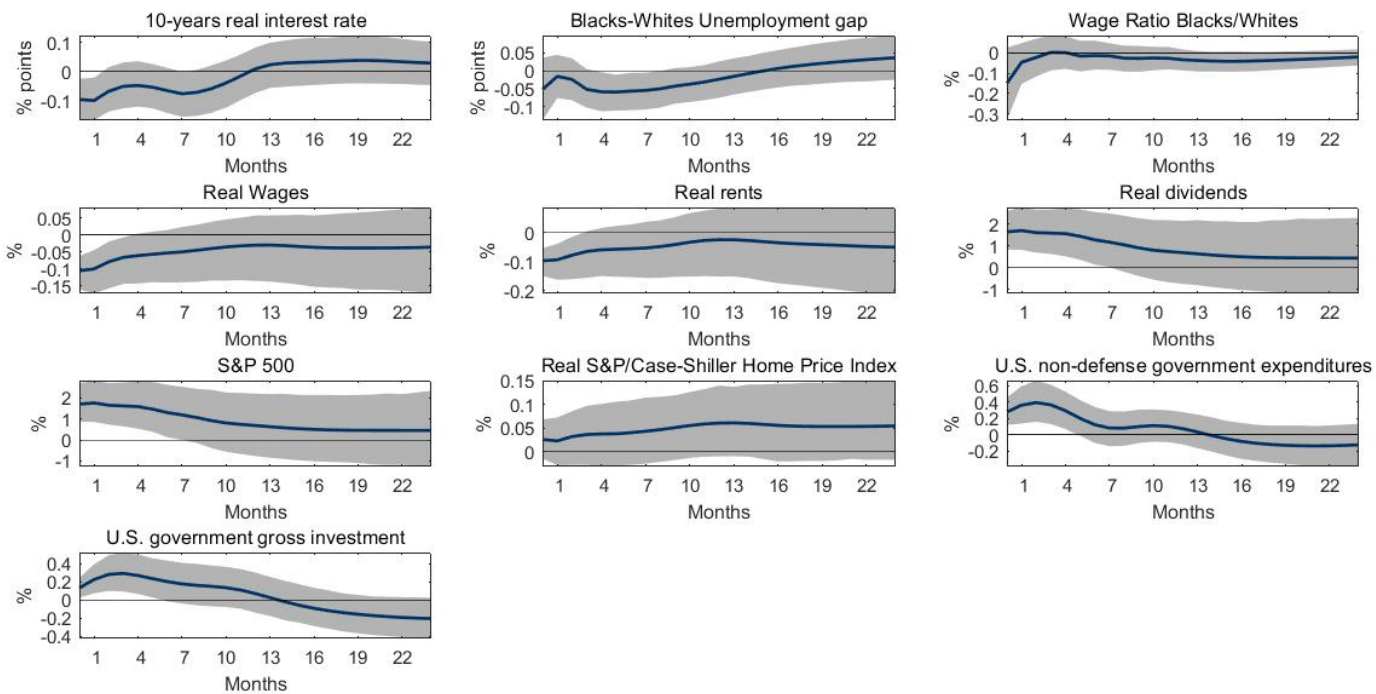

Note: IRFs to a 20 basis point decrease in the one-year government treasury bill for the monetary policy transmission channels from the baseline. Sample: 1982M1:2014M2. Shaded regions represent 90\% posterior confidence bands.

\subsection{Robustness checks}

To check the validity of the results with respect to the representatives of each inequality channel, we estimate a different baseline specification. Specifically, we consider the unemployment gap between Hispanics and American whites as representative for the extensive margin of the earnings heterogeneity channel. The (log) real stock price index (Dow Jones) is considered as the indicator for the portfolio channel, whereas the U.S. defense expenditures for the fiscal channel. The resulting IRFs are provided in figure 5. According to the earnings heterogeneity channel, specifically in the extensive margin, an expansionary monetary policy shock by 20 basis points has no statistically significant response on the unemployment gap between Hispanics and American whites workers. This result is also obtained by Carpenter and Rodgers 
(2004). We obtain a similar response in magnitude and significance for the portfolio channel. For the fiscal channel, a monetary policy shock increases U.S. defense expenditures. In particular, the increase in fiscal policy is significant between the sixth and the tenth months after the shock reaching a peak of 0.24 percent. We observe that loosening monetary policy also increases fiscal expenditures as the results for the baseline model. In addition, note that the responses of the remaining inequality channels that do not change their specifications are similar to the IRFs of the baseline. Thus, this result suggest the robustness of the analysis with regard to the baseline specification.

Figure 5: Alternative inequality transmission channels for the baseline
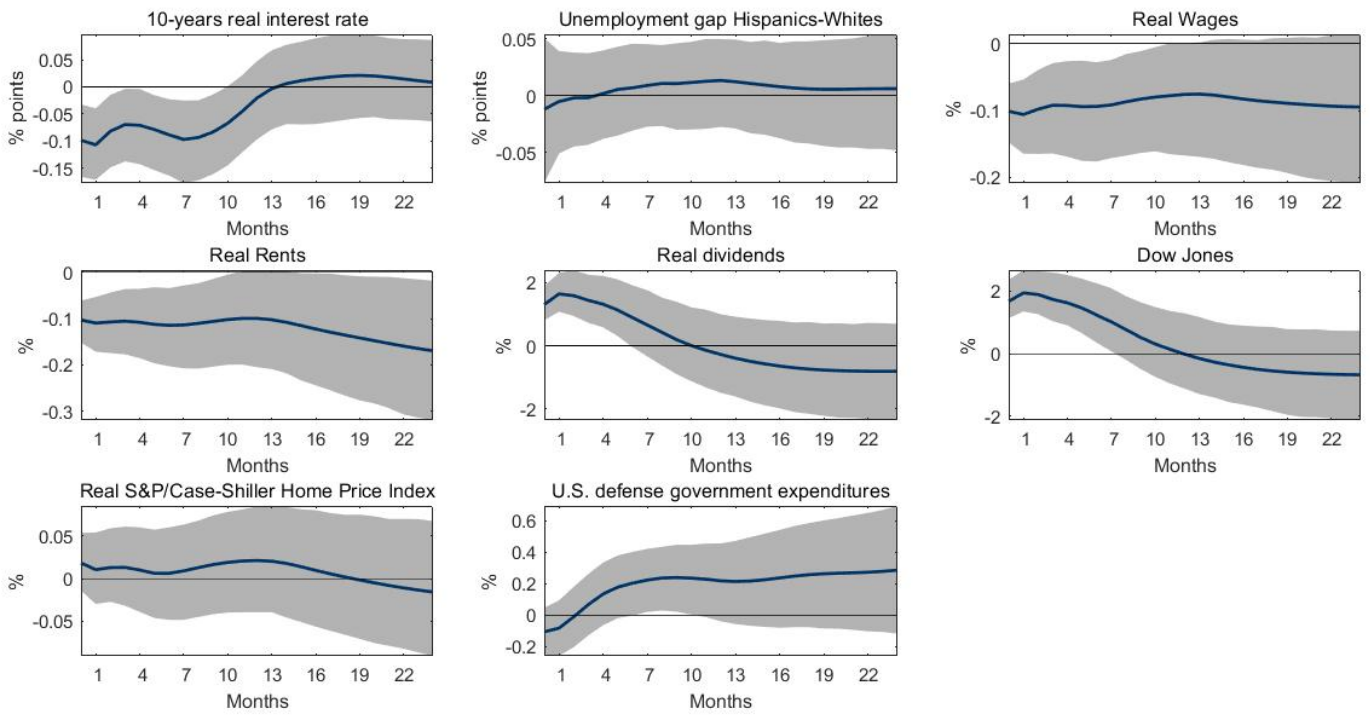

Note: IRFs to a 20 basis point decrease in the one-year government treasury bill for the alternative monetary policy transmission channels from the baseline. Sample: 1982M1:2014M2. Shaded regions represent 90\% posterior confidence bands.

Given that the sample of the baseline considered contains the zero lower 
bound period, the use of the one-year government treasury bill rate as policy indicator to reflect the stance of monetary policy limits the informativeness of the Federal Reserve rate. To check the validity of the results with respect to the recent years of the estimation sample, we first estimate the responses of the baseline using the $\mathrm{Wu}$ and Xia (2016) shadow rate instead of the policy indicator adopted in the baseline. Figures D.7 D.8 show the IRFs considering the shadow rate. As can be observed, the responses are similar to the IRFs provided by using the the one-year government treasury bill rate. In addition, the responses of the direct inequality measures and the inequality channels have similar magnitude. The baseline is also estimated up to 2008 where the federal fund rate reached the zero lower bound and unconventional monetary policy measures began to be applied. The resulting IRFs are provided in figures D.9 D.10. The responses on inequality are similar to the IRFs for the baseline estimated using all the sample. According to the inequality channels, the magnitude of the IRFs is identical and the responses are slightly less statistically significant. Overall, the results are not affected by the inclusion of the recent period after the financial crisis.

In addition, we also account for the several dimensions of monetary policy actions during the zero lower bound period considering the two factors of Swanson (2015) as proxies for forward guidance and large-scale asset purchases (LSAP) policies respectively 6 . Figures D.11 D.12 and figures D.13. D.14 show the responses to a forward guidance and LSAP monetary policy shock respectively. The IRFs have practically similar direction and significance with respect to the baseline. According to the responses to a LSAP

\footnotetext{
${ }^{6}$ We thank Eric Swanson for sharing with us the monetary policy shocks.
} 
monetary policy shock, only the income composition and portfolio channels are statistically significant. However, results are similar for the direct measures of inequality. Thus, we can conclude that results on inequality are robust to the consideration of different monetary policy shocks.

On the other hand, we estimate the baseline considering the indications of the Schwarz bayesian criteria (SBC). Hence, we set the lag length to three following the SBC. Figures D.15 D.16 display the results considering this lag length criterion. As can be observed, the significance levels and the magnitude of the responses are analogous to the IRFs for the baseline considering the AIC. The magnitude of the responses on inequality adopting the SBC are slightly smaller than under the AIC. Thus, the results are robust to the adoption of different lag length criteria.

To check the robustness of the results with respect to the potential misspecification of the VAR adopted in the baseline, we consider the estimation of the baseline with the methodology of Bayesian Local Projections (BLP) proposed by Miranda-Agrippino and Ricco (2018b). This methodology has the flexibility of LP and the robustness to control for mispecification that may be present in VAR. If the baseline consider is misspecified, the IRFs will be biased with respect to the responses using BLP. Figures D.17D.18 show the IRFs under the BLP approach. As can be observed, the magnitude of the IRFs is similar to the baseline estimated by Bayesian proxy SVAR. Thus, results suggest that the VAR model specification do not suffer for misspecification. 


\section{Conclusions}

The rise in income and wealth inequality in the U.S. in recent years has increased the attention of academics and policymakers on the redistributive effects of monetary policy. In this paper, we assess the effects of monetary policy shocks on income and wealth inequality in the U.S. through direct inequality measures and by analyzing several transmission channels explored in recent literature. In addition, we assess two new channels less considered by previous research, these are the housing and the fiscal channels. For this purpose, we use a Bayesian proxy structural vector auto-regression (proxy SVAR) constructing our own monetary shocks. Using several direct measures of wealth distribution, our findings suggest that an expansionary monetary policy shock increases wealth inequality. The increases in wealth inequality could be explained due to the portfolio channel. However, we do not find any significant response when we assess the final effect of monetary policy on income inequality. We find that expansionary monetary policy could reduce income inequality through saving redistribution, earnings heterogeneity as well as the fiscal and the housing channels. However, the opposite result is found when we analyze the income composition channel due to the contracyclical behavior of real wages and the pro-cyclical reaction of real dividends.

The complexity of the mechanisms that link monetary policy and inequality is due to the fact that there are several channels that have an impact in the opposite direction that leads to an uncertain net effect. An adequate study of the distributional effects of monetary policy taking into account all potential channels is important not only to improve our knowledge of the side effects of monetary measures applied by central banks, especially after 
the financial crisis, but also for the effectiveness of the monetary policy itself.

It is clear that the objective of the Federal Reserve is and should be to fulfill its mandate to achieve maximum employment and price stability, thus providing broad benefits to the economy. In addition, other types of policies are more appropriate to address concerns about inequality (fiscal policy or income policy). However, the most recent research indicates that monetary policies can also have important distributive effects and should be taken into account when properly designing these policies.

\section{Acknowledgments}

This work is partially funded by project TIN2016-80565-R Design and development of high performance algorithms for finding the best econometric model and its application to health science problems facing the Spanish Government. This research was supported by the FPU grant (FPU16/03957) from the Spanish Ministry of Education, Culture and Sport to the first author of this research. 


\section{References}

Albert, J.F., Gómez-Fernández, N., 2018. Monetary policy and the redistribution of net worth in the U.S. Working Paper, London School of Economics and Political Science .

Albert, J.F., Gómez-Fernández, N., Ochando, C., 2019. Effects of unconventional monetary policy on income and wealth distribution: Evidence from United States and Eurozone. Panoeconomicus 66, 535-558.

Ameriks, J., Zeldes, S.P., 2004. How do household portfolio shares vary with age. Technical Report. Columbia University.

Berisha, E., Meszaros, J., Olson, E., 2018. Income inequality, equities, household debt, and interest rates: Evidence from a century of data. Journal of International Money and Finance 80, 1-14.

Bernanke, B.S., 2015. Monetary policy and inequality. Ben Bernanke's Blog at Brookings .

Bernanke, B.S., Boivin, J., Eliasz, P., 2005. Measuring the effects of monetary policy: a factor-augmented vector autoregressive (FAVAR) approach. The Quarterly Journal of Economics 120, 387-422.

Bernanke, B.S., Kuttner, K.N., 2005. What explains the stock market's reaction to Federal Reserve policy? The Journal of Finance 60, 12211257.

Bilias, Y., Georgarakos, D., Haliassos, M., 2010. Portfolio inertia and stock market fluctuations. Journal of Money, Credit and Banking 42, 715-742. 
Blanchard, O., 1995. Macroeconomic implications of shifts in the relative demand for skills. Economic Policy Review , 48-53.

Bonnet, O., Bono, P.H., Chapelle, G., Wasmer, E., 2014. Does housing capital contribute to inequality? a comment on Thomas Piketty's Capital in the 21st Century. Sciences Po Economics Discussion Papers 7, 12.

Boot, J.C., Feibes, W., Lisman, J.H.C., 1967. Further methods of derivation of quarterly figures from annual data. Applied Statistics , 65-75.

Brunnermeier, M.K., Sannikov, Y., 2012. Redistributive monetary policy, in: Jackson Hole Symposium, Federal Reserve Bank of Kansas City Kansas City, KS. pp. 331-384.

Cantillon, R., 1755. Essay on the nature of general commerce. Henry Higgs, trans. London: Macmllan .

Carpenter, Seth Ihrig, J., Klee, E., Quinn, D., Boote, A., 2015. The Federal Reserve's balance sheet and earnings: A primer and projections. International Journal of Central Banking 11, 237-283.

Carpenter, S.B., Rodgers, W.M., 2004. The disparate labor market impacts of monetary policy. Journal of Policy Analysis and Management 23, 813830.

Coibion, O., Gorodnichenko, Y., Kueng, L., Silvia, J., 2017. Innocent bystanders? Monetary policy and inequality. Journal of Monetary Economics $88,70-89$. 
Colciago, A., Samarina, A., de Haan, J., 2019. Central bank policies and income and wealth inequality: A survey. Journal of Economic Surveys 33, 1199-1231.

Dahan, M., 1998. The fiscal effects of monetary policy. International Monetary Fund 98, 1-19.

Davtyan, K., 2017. The distributive effect of monetary policy: The top one percent makes the difference. Economic Modelling 65, 106-118.

Doepke, M., Schneider, M., 2006. Inflation and the redistribution of nominal wealth. Journal of Political Economy 114, 1069-1097.

Dolado, J., Motyovszki, G., Pappa, E., 2018. Monetary policy and inequality under labor market frictions and capital-skill complementarity. CEPR Discussion Paper No. DP12734 .

Domanski, D., Scatigna, M., Zabai, A., 2016. Wealth inequality and monetary policy. BIS Quarterly Review March .

Duarte, J.B., Dias, D.A., 2016. Housing and monetary policy in the business cycle: What do housing rents have to say. Technical Report. Mimeo 11.

El Herradi, M., Leroy, A., 2019. Monetary policy and the top one percent: Evidence from a century of modern economic history. De Nederlandsche Bank Working Paper .

Finer, D.A., 2018. What insights do taxi rides offer into Federal Reserve leakage? Chicago Booth: George J. Stigler Center for the Study of the Economy \& the State Working Paper . 
Furceri, D., Loungani, P., Zdzienicka, A., 2017. The effects of monetary policy shocks on inequality. Journal of International Money and Finance .

Gagnon, J., 2010. Large-scale asset purchases by the Federal Reserve: Do they Work? Staff Report Federal Reserve Bank of New York.

Galbraith, J.K., 2000. Created unequal: The crisis in American pay. University of Chicago Press.

Gerko, E., Rey, H., 2017. Monetary policy in the capitals of capital. Journal of the European Economic Association 15, 721-745.

Gertler, M., Karadi, P., 2015. Monetary policy surprises, credit costs, and economic activity. American Economic Journal: Macroeconomics 7, 44-76.

Gilchrist, S., Zakrajšek, E., 2012. Credit spreads and business cycle fluctuations. American Economic Review 102, 1692-1720.

Gürkaynak, R.S., Sack, B., Swansonc, E.T., 2005. Do actions speak louder than words? the response of asset prices to monetary policy actions and statements. International Journal of Central Banking .

Heathcote, J., Perri, F., Violante, G.L., 2010. Unequal we stand: An empirical analysis of economic inequality in the United States, 1967-2006. Review of Economic dynamics 13, 15-51.

Inui, M., Sudou, N., Yamada, T., 2017. The effects of monetary policy shocks on inequality in Japan. BIS Working Paper .

Kuhn, M., Schularick, M., Steins, U., 2019. Income and wealth inequality in America, 1949-2016. CESifo Working Paper, No. 7726 . 
Kuttner, K.N., 2001. Monetary policy surprises and interest rates: Evidence from the fed funds futures market. Journal of monetary economics 47, $523-544$.

Kuttner, K.N., 2012. Low interest rates and housing bubbles: still no smoking gun. The Role of Central Banks in Financial Stability: How Has It Changed, 27.

Leeper, E.M., Leith, C., 2016. Understanding inflation as a joint monetaryfiscal phenomenon, in: Handbook of Macroeconomics. Elsevier. volume 2, pp. 2305-2415.

Lenza, M., Slacalek, J., 2018. How does monetary policy affect income and wealth inequality? evidence from the euro area. European Central Bank, mimeo .

Litterman, R.B., 1986. Forecasting with Bayesian vector autoregressions - five years of experience. Journal of Business \& Economic Statistics 4, 25-38.

Mertens, K., Ravn, M.O., 2013. The dynamic effects of personal and corporate income tax changes in the United States. American Economic Review $103,1212-47$.

Miranda-Agrippino, S., 2016. Unsurprising shocks: information, premia, and the monetary transmission. Bank of England Working Paper .

Miranda-Agrippino, S., Ricco, G., 2018a. Bayesian vector autoregressions. Centre For Macroeconomics, London School of Economics and Political Science . 
Miranda-Agrippino, S., Ricco, G., 2018b. The transmission of monetary policy shocks. CEPR Discussion Paper No. DP13396 .

Mumtaz, H., Theophilopoulou, A., 2017. The impact of monetary policy on inequality in the U.K. an empirical analysis. European Economic Review $98,410-423$.

Nakajima, M., 2015. The redistributive consequences of monetary policy. Federal Reserve Bank of Philadelphia, Business Review Q 2, 9-16.

Nakamura, E., Steinsson, J., 2018. High-frequency identification of monetary non-neutrality: the information effect. The Quarterly Journal of Economics 133, 1283-1330.

Normandin, M., 2006. The effects of monetary-policy shocks on real wages: A multi-country investigation. HEC Montréal, Institut d'économie appliquée.

O’Farrell, R., Rawdanowicz, Ł., Inaba, K.I., 2016. Monetary policy and inequality. OECD Publishing .

Perry, B., Phillips, K.L., Spencer, D.E., 2015. State-level variation in the real wage response to monetary policy. Annals of Economics \& Finance 16.

Piazzesi, M., Schneider, M., 2016. Housing and macroeconomics, in: Handbook of Macroeconomics. Elsevier. volume 2, pp. 1547-1640.

Ramey, V.A., 2016. Macroeconomic shocks and their propagation, in: Handbook of Macroeconomics. Elsevier. volume 2, pp. 71-162. 
Saiki, A., Frost, J., 2014. Does unconventional monetary policy affect inequality? evidence from Japan. Applied Economics 46, 4445-4454.

Samarina, A., Nguyen, A.D., 2019. Does monetary policy affect income inequality in the euro area? De Nederlandsche Bank Working Paper .

Sims, C.A., 2013. Paper money. American Economic Review 103, 563-84.

Sims, C.A., Zha, T., 1999. Error bands for impulse responses. Econometrica $67,1113-1155$.

Stock, J.H., Watson, M.W., 2012. Disentangling the Channels of the 20072009 Recession. Technical Report. National Bureau of Economic Research.

Stock, J.H., Wright, J.H., Yogo, M., 2002. A survey of weak instruments and weak identification in generalized method of moments. Journal of Business \& Economic Statistics 20, 518-529.

Swanson, E.T., 2015. Measuring the effects of unconventional monetary policy on asset prices. Technical Report. National Bureau of Economic Research.

Szymborska, H.K., 2019. Wealth structures and income distribution of us households before and after the great recession. Structural Change and Economic Dynamics 51, 168-185.

Williamson, S.D., 2008. Monetary policy and distribution. Journal of Monetary Economics 55, 1038-1053. 
Wolff, E.N., 2016. Deconstructing Household Wealth Trends in the United States, 1983-2013. Technical Report. National Bureau of Economic Research.

Wu, J.C., Xia, F.D., 2016. Measuring the macroeconomic impact of monetary policy at the zero lower bound. Journal of Money, Credit and Banking 48, 253-291. 


\section{Appendix A. Responses of economic and financial variables}

Figure A.6: Economic and financial variables for the baseline
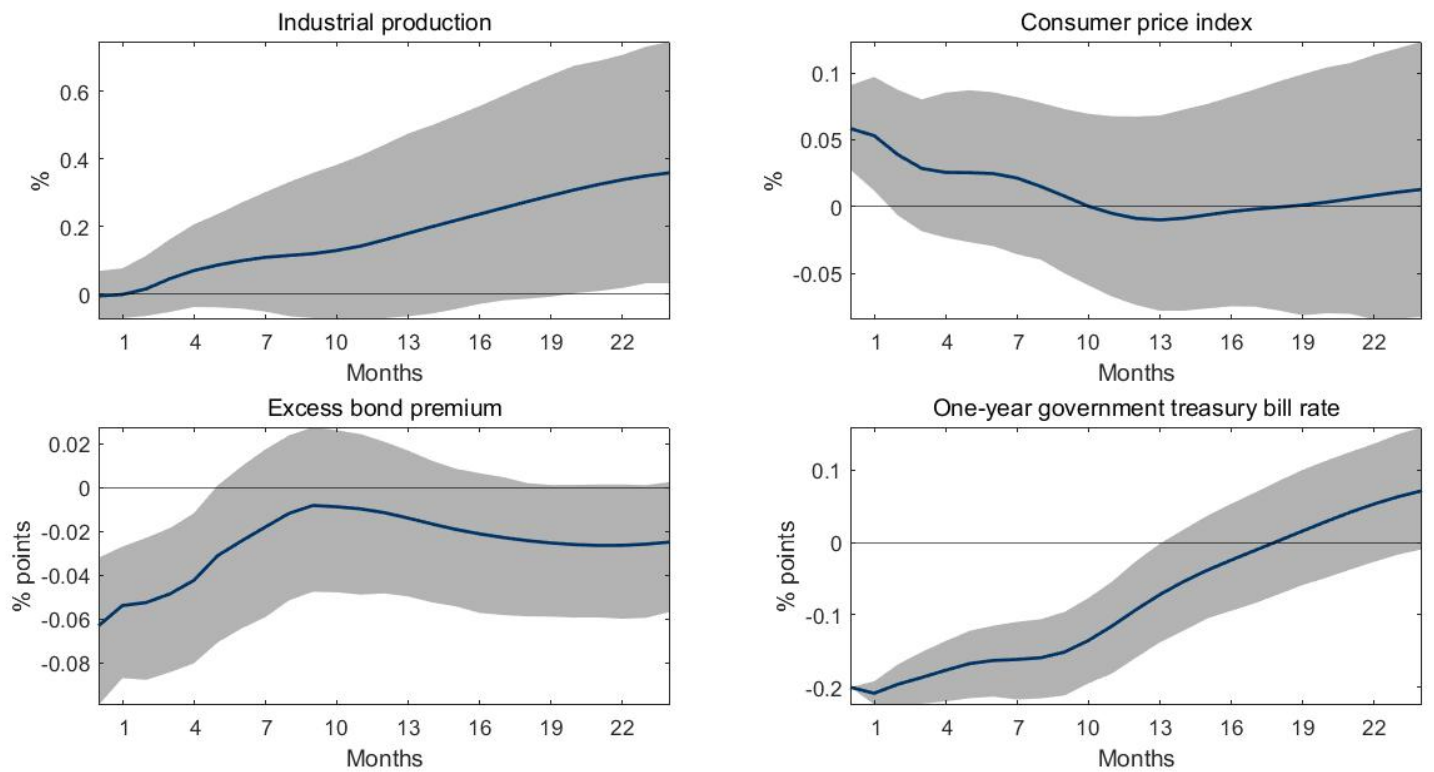

Note: IRFs to a 20 basis point decrease in the one-year government treasury bill for IP, CPI, EBP and GS1 from the baseline. Sample: 1982M1:2014M2. Shaded regions represent $90 \%$ posterior confidence bands.

\section{Appendix B. Construction of variables}

We show in this appendix the construction of the variables we use in our analysis.

First, note that all the Gini indexes of inequality used in this paper are only available on annual basis and our SVARs models are estimated in monthly frequency. Given that Gini direct measures of inequality have low variation, the interpolation to monthly frequency is justifiable. We follow Davtyan (2017) to interpolate the Gini indexes. Specifically, we use the first difference approach of Boot et al. (1967). Data for the annual Gini coeffi- 
cients are disaggregated to monthly frequency such that the average of the interpolated series is equal to the corresponding aggregate value. As direct measures of income and wealth inequality, we use the interpolated Gini coefficient from the World Inequality Database (WID). We take these variables on annual basis from 1982 to 2014 (last available year) to interpolate the Gini coefficients from annual frequency to monthly series. In addition, to check our direct effect on income inequality we use the Gini index of pre-tax income and the Gini index of post-tax income provided by Coibion ? These variables are constructed from the Consumer Expenditure Survey (CEX) and carefully explained by Coibion et al. (2017). The period of these variables are only available from 1980Q1 to 2008Q4. Thus, we interpolate the series to monthly frequency.

To assess the final effect of monetary policy on wealth distribution taking into account the portfolio and housing channels, we built micro-level data series with the evolution of real stock prices and real house prices. According to Wolff (2016), the wealth distribution of the different groups is surprisingly similar over time. Hence, we have built the series for different wealth groups (top 1, next 19 per cent and Middle 3 quintiles) calculating the changes in stock and house prices in each month for each wealth group, taking into account the proportion of wealth that each group holds in different assets. This proportion can be found in table B.1. Taking this distinction into account, we want to see how an expansive monetary policy affects the wealth of the different groups according to the assets that each group holds. As shown in Table B.1, in 2016, the richest one percent of households (ranked by wealth),

\footnotetext{
${ }^{7}$ We thank Olivier Coibion for providing us these income inequality measures.
} 
held only 7.6 per cent of their wealth in housing, conversely, they invested 80 percent of their savings in investment real estate, businesses, corporate stock, and financial securities. On the other hand, we can see that the middle three quintiles held, in the same year, 61.9 per cent of their wealth in housing and around of 12 per cent in financial investments. As the distribution of liquid assets is similar across the three wealth groups and does not represent much of total wealth, we exclude it from our analysis. This analysis assumes that households do not adjust their portfolios in response to monetary policy. A similar estimation is undertaken by Lenza and Slacalek (2018) for the Eurozone. As they argue, this seems a reasonable approximation according to the evidence found by Wolff (2016) Ameriks and Zeldes (2004) or Bilias et al. (2010). All of them provide evidence for the sluggishness in household portfolios in both illiquid and financial assets.

Table B.1: Household Wealth Composition (2016)

\begin{tabular}{|c|c|c|c|c|}
\hline $\begin{array}{c}\text { Percent of gross assets } \\
\text { 2016 }\end{array}$ & Top 1\% & Next 19\% & $\begin{array}{c}\text { Middle 3 } \\
\text { Quintiles }\end{array}$ & $\begin{array}{c}\text { All } \\
\text { Households }\end{array}$ \\
\hline Principal Residence & 7.6 & 25.6 & 61.9 & 25.1 \\
Liquid assets & 4.6 & 7.7 & 8.5 & 6.7 \\
Financial investments (Without pensions) & 80.4 & 43.1 & 11.8 & 51.3 \\
Pensions accounts and other assets & 7.4 & 23.6 & 17.8 & 16.9 \\
Total assets & 100 & 100 & 100 & 100 \\
\hline
\end{tabular}

Source: author's calculations based on Wolff (2016) from the 2016 SCF. Households are classified into wealth class according to their net worth. Brackets for 2016 are:

Top one percent: Net worth of $\$ 10,257,000$ or more.

Next 19 percent: Net worth between $\$ 471,600$ and $\$ 10,257,000$.

Quintiles 2 through 4: Net worth between $\$ 0$ and $\$ 471,600$.

Second, to explore the transmission channels we use the following variables: 
For the saving redistribution channel, the ten-year real interest rate is used as representative. We take the difference between the ten-year nominal interest rate and the inflation rate of the consumer price index (CPI) to obtain the real interest rate. Both variables are obtained from Datastream.

To assess the extensive margin of the earnings heterogeneity channel we follow Carpenter and Rodgers (2004) to construct the ethnic differences in unemployment rates. The unemployment rate data is directly taken from Datastream. Likewise, to explore the intensive margin of the the earnings heterogeneity channel we use the ratio between labour earnings of white Americans and black workers. To build the labour earnings of each racial groups, we use data from the NBER extracts of the Current Population Survey (CPS) Merged Outgoing Rotation Groups. The extracts contain data on employment, education level, employment status and earnings as well as background variables as race, sex, age and geographic location, among others. The individuals included in the sample are those of working age (from 15 to 64 years), and those that are neither war veterans nor part-time workers nor self-employed. CPS provides monthly data from 1979 to 2017. Labour earnings series for each race were constructed by the ratio between weekly earnings and usual hours worked.

To analyze the income composition channel, first, we use the real wages defined as the average hourly earnings of production and non supervisory employees (private) deflated by the CPI. We take the nominal and price deflator from Datastream. Second, we use the real dividends directly taken from Robert Shiller's webpage.

To assess the portfolio channel, we use the (log) real stock price index (SP 
$500)$ and the $(\log )$ real stock price index (Dow Jones) to check the results. Both indices have been obtained from Datastream.

Real S\&P/Case-Shiller national home price directly taken from Robert Shiller's webpage and real rents defined as rent of primary residence deflacted by CPI from Datastream are used to explore the housing channel.

For assessing the fiscal channel, we use the U.S. non-defense Government expenditures and the U.S. gross government investment. These data are collected by Datastream in quarterly frequency. Quarterly data is seasonally adjusted with X-ARIMA-13 and linearly interpolated to monthly frequency. We convert it to real terms using the CPI.

The rest of the variables of the model are taken from Datasteam. These are the consumer price index, the industrial production index and the excess bond premium which is a financial indicator built by Gilchrist and Zakrajšek (2012).

As policy indicator we have used the one-year Government treasury bill yield collected by Datastream and to conduct a robustness check we use the Wu-Xia shadow rate developed by Wu and Xia (2016).

Finally, our own monetary policy shocks are built using intraday Federal Fund futures obtained by www.tickdatamarket.com (see last section for further details on the construction of the shocks) 


\section{Appendix C. First-stage regression}

Table C.2: First-stage regression for each specification

\begin{tabular}{|c|c|}
\hline First-Stage Regression & F-statistic \\
\hline Baseline & 26.36 \\
Baseline using Gini index of Wealth Inequality & 22.33 \\
Baseline using Coibion et al. (2017) income inequality measures & 21.12 \\
Baseline using alternative specifications for the inequality channels & 25.25 \\
Baseline up to 2008 & 23.33 \\
Baseline using the Wu and Xia (2016) shadow rate & 25.94 \\
Baseline using SBC criterion & 30.28 \\
Baseline using Bayesian Local Projections & 24.86 \\
\hline
\end{tabular}

For all cases, results on first-stage regression show that the relevance condition is satisfied. The F-statistic is widely above the threshold suggested by Stock et al. (2002) and therefore we avoid weak instrument problems. 


\section{Appendix D. Robustness checks}

Figure D.7: Inequality measures for the baseline considering the shadow rate
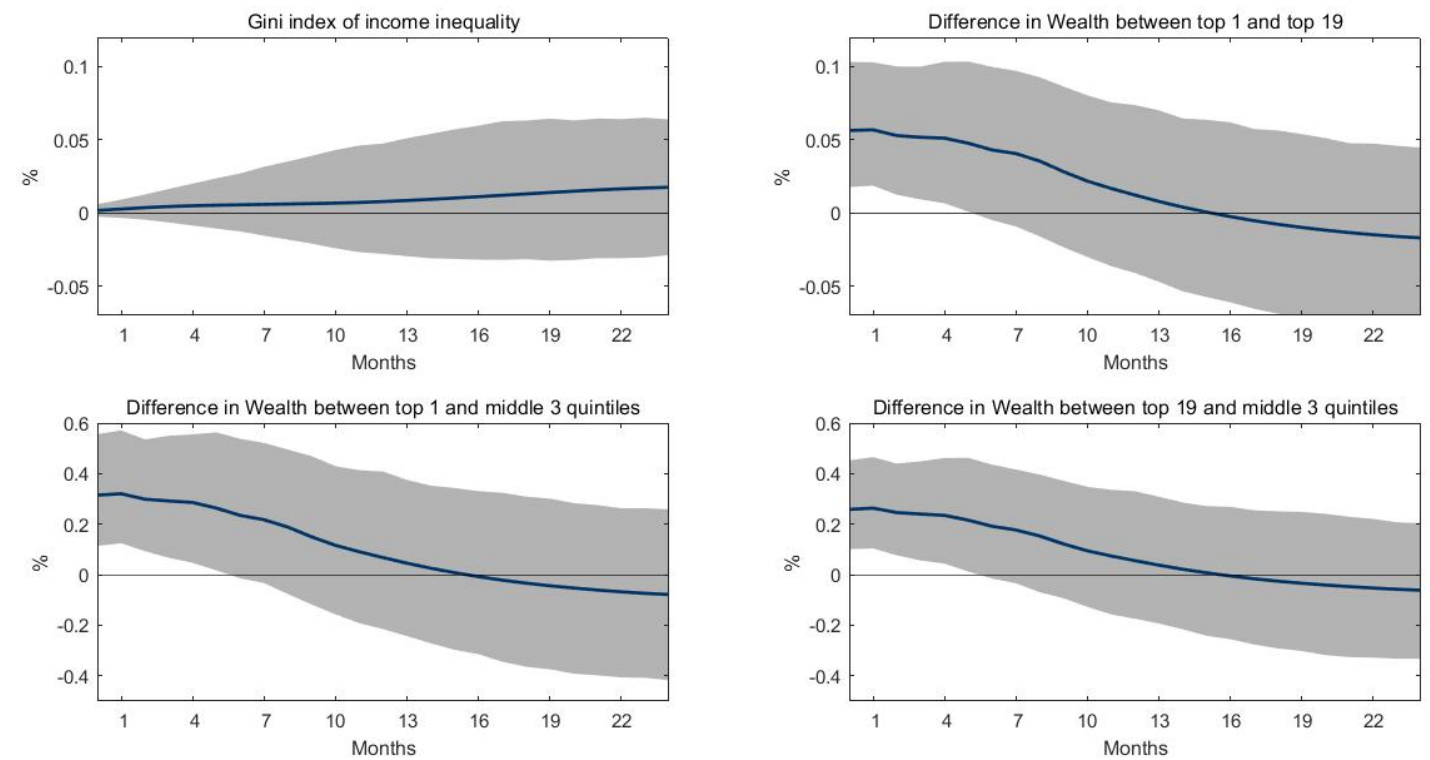

Note: IRFs to a 20 basis point decrease in the one-year government treasury bill for the direct measures of income and wealth inequality from the baseline considering the $\mathrm{Wu}$ and Xia (2016) shadow rate. Sample: 1982M1:2014M2.

Shaded regions represent $90 \%$ posterior confidence bands. 
Figure D.8: Inequality transmission channels for the baseline considering the shadow rate
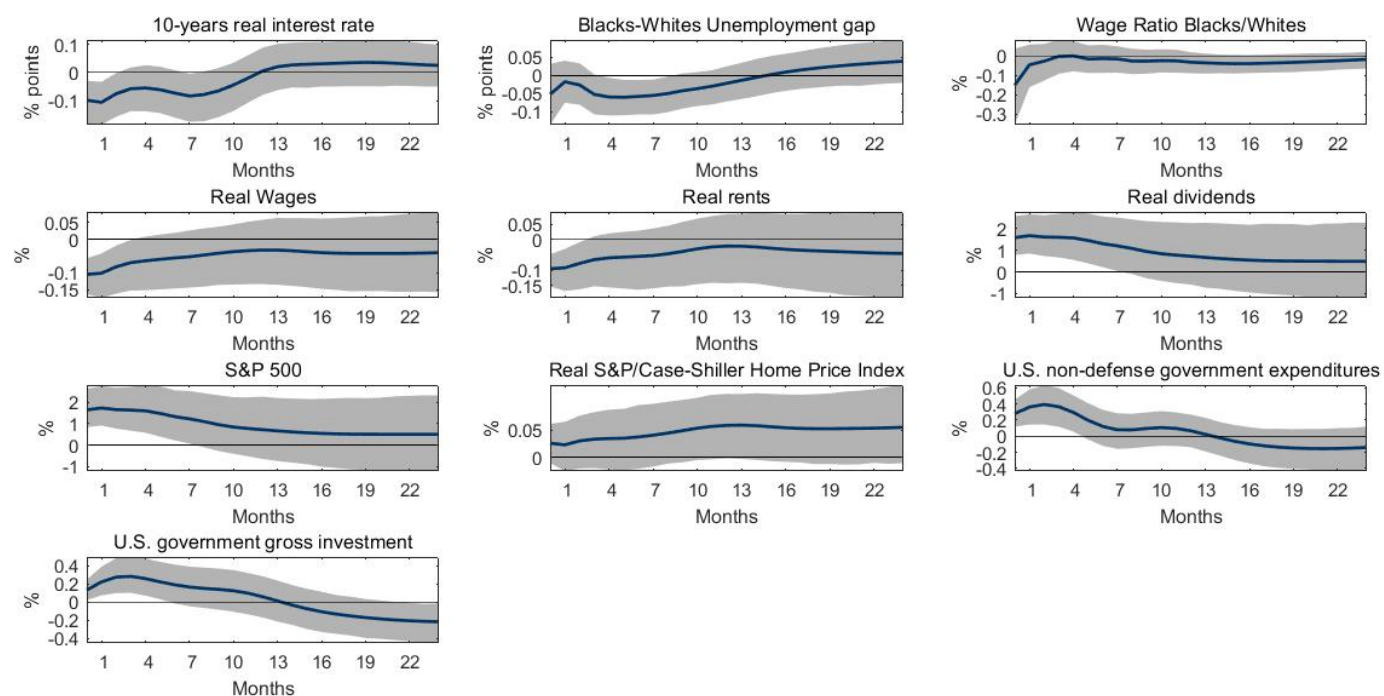

Note: IRFs to a 20 basis point decrease in the one-year government treasury bill for the monetary policy transmission channels from the baseline considering the Wu and Xia (2016) shadow rate. Sample: 1982M1:2014M2. Shaded regions represent $90 \%$ posterior confidence bands. 
Figure D.9: Inequality measures for the baseline before the financial crisis
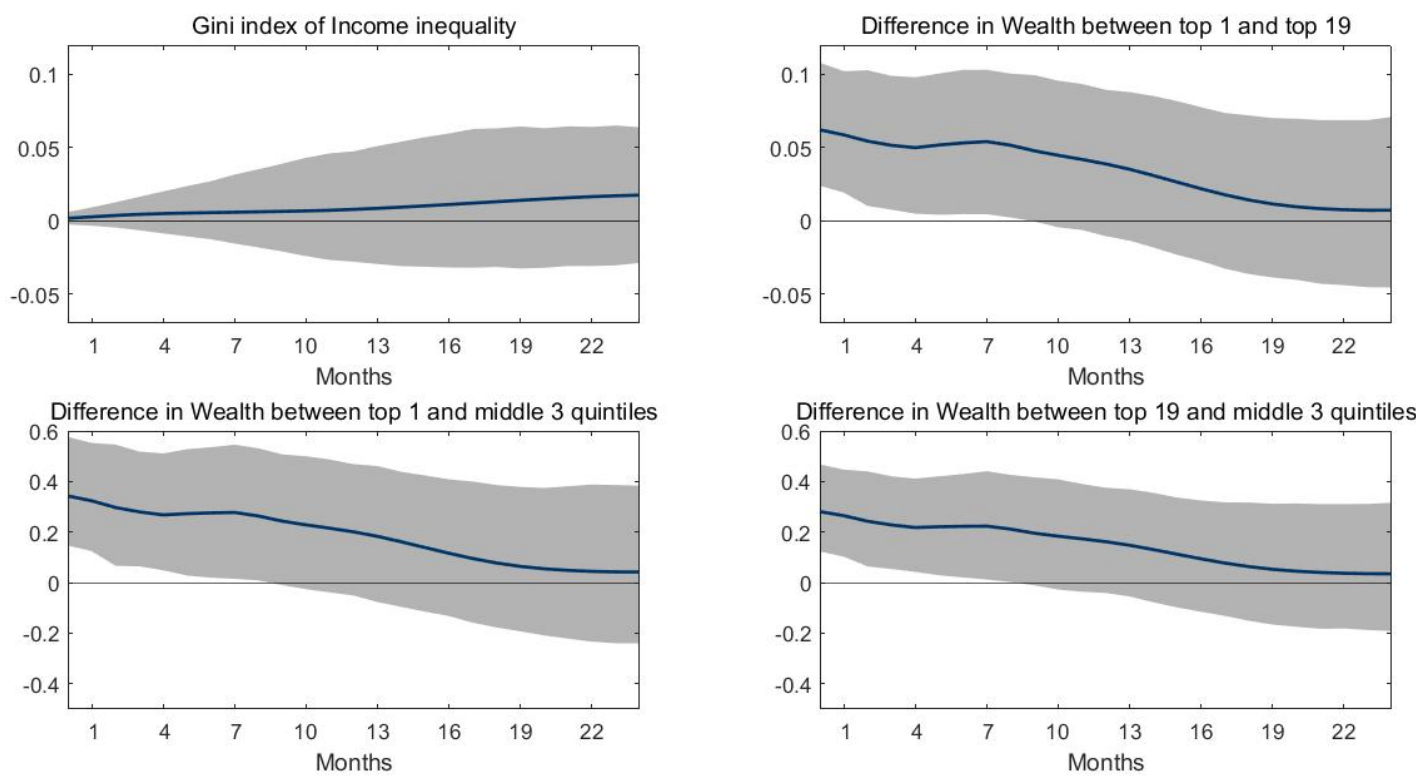

Note: IRFs to a 20 basis point decrease in the one-year government treasury bill for the direct measures of income and wealth inequality from the baseline. Sample: 1982M1:2008M8. Shaded regions represent 90\% posterior confidence bands. 
Figure D.10: Inequality transmission channels for the baseline before the financial crisis
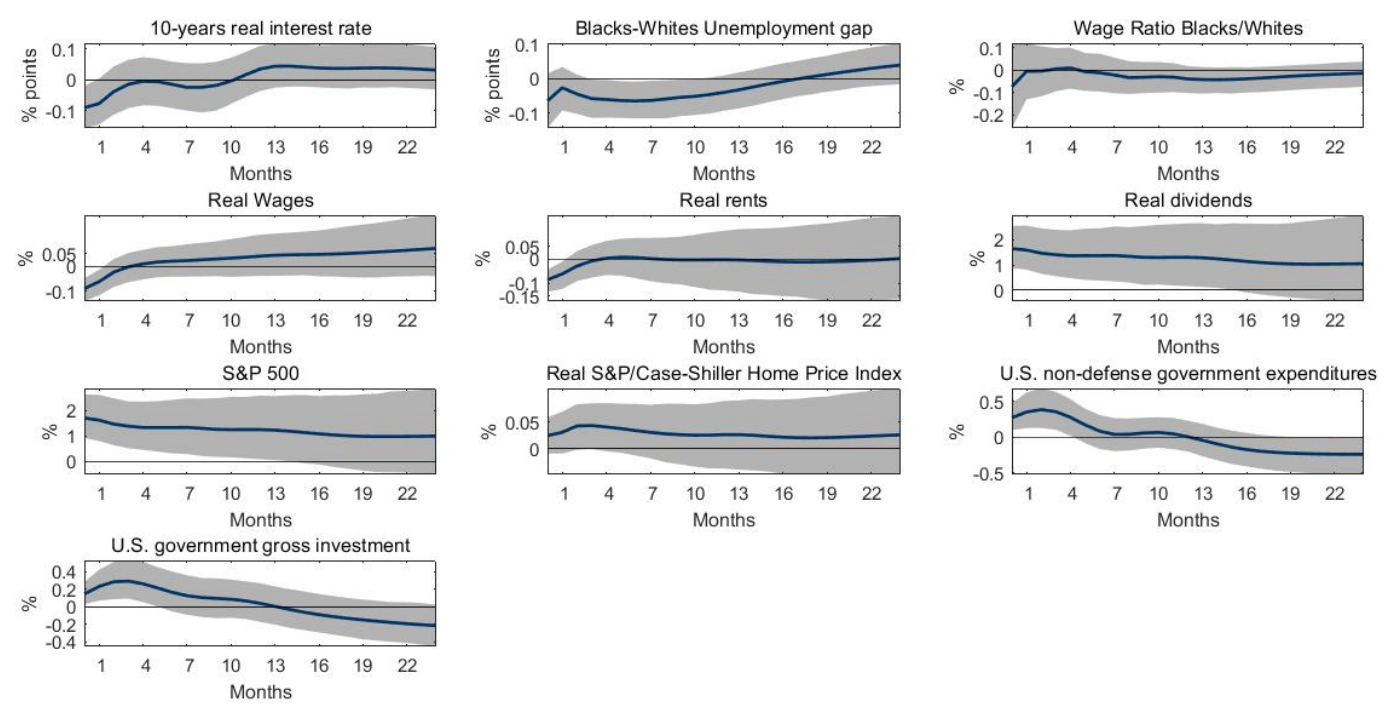

Note: IRFs to a 20 basis point decrease in the one-year government treasury bill for the monetary policy transmission channels from the baseline. Sample: 1982M1:2008M8. Shaded regions represent 90\% posterior confidence bands. 
Figure D.11: Inequality measures for the baseline after a forward guidance monetary policy shock

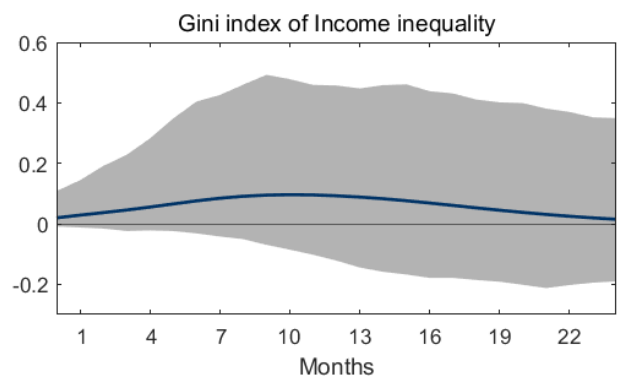

Difference in Wealth between top 1 and middle 3 quintiles

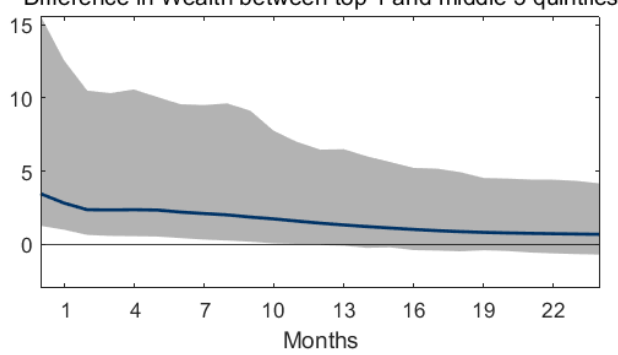

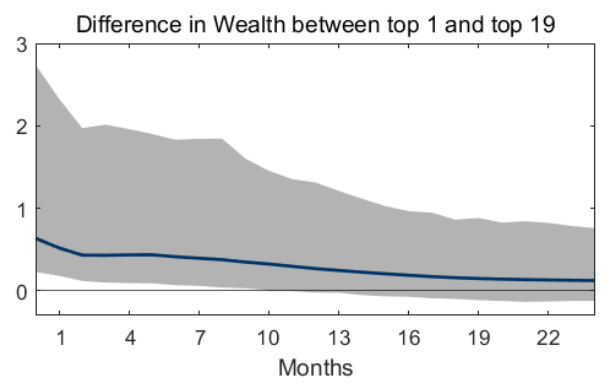

Difference in Wealth between top 19 and middle 3 quintiles

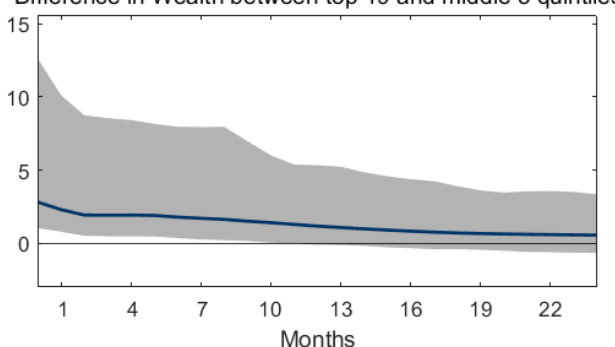

Note: IRFs to a 20 basis point decrease in the one-year government treasury bill for the direct measures of income and wealth inequality from the baseline.

Sample: 1982M1:2012M12. Shaded regions represent 90\% posterior confidence bands. 
Figure D.12: Inequality transmission channels for the baseline after a forward guidance monetary policy shock
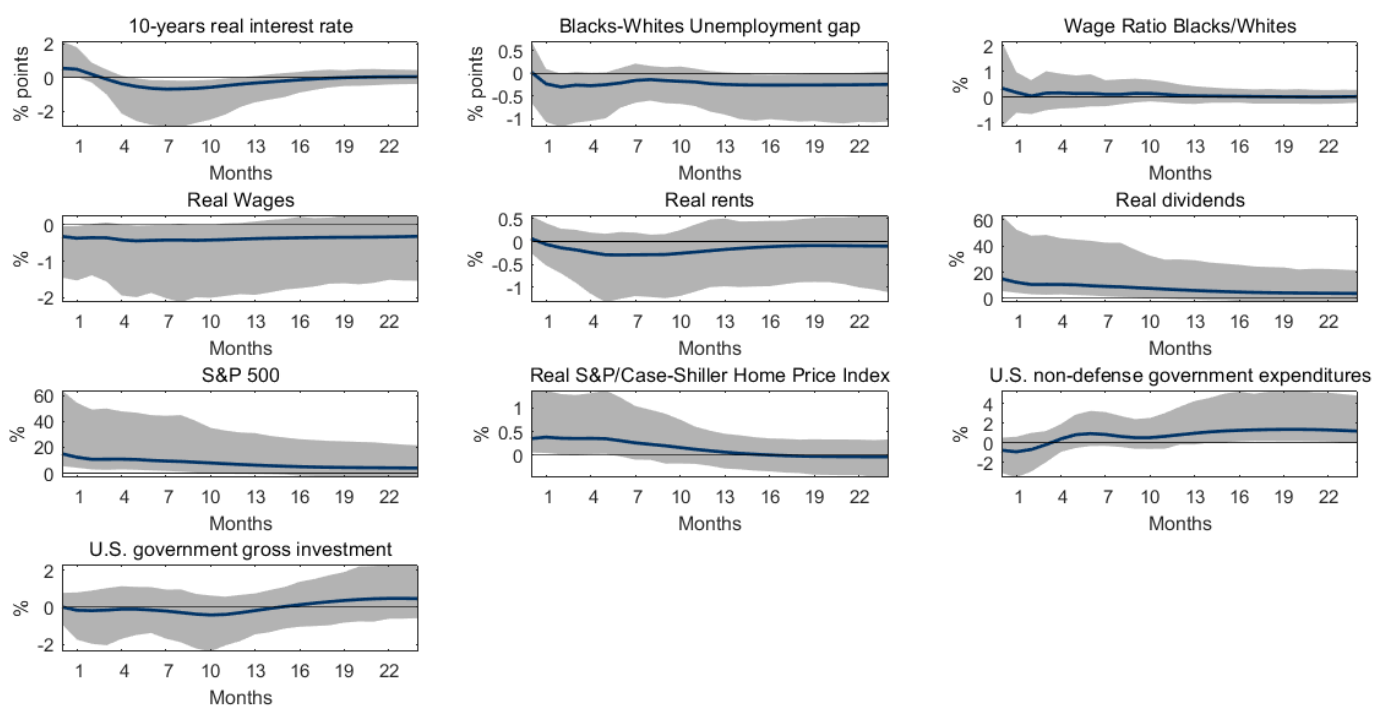

Note: IRFs to a 20 basis point decrease in the one-year government treasury bill

for the monetary policy transmission channels from the baseline. Sample: 1982M1:2012M12. Shaded regions represent 90\% posterior confidence bands. 
Figure D.13: Inequality measures for the baseline after a LSAP monetary policy shock
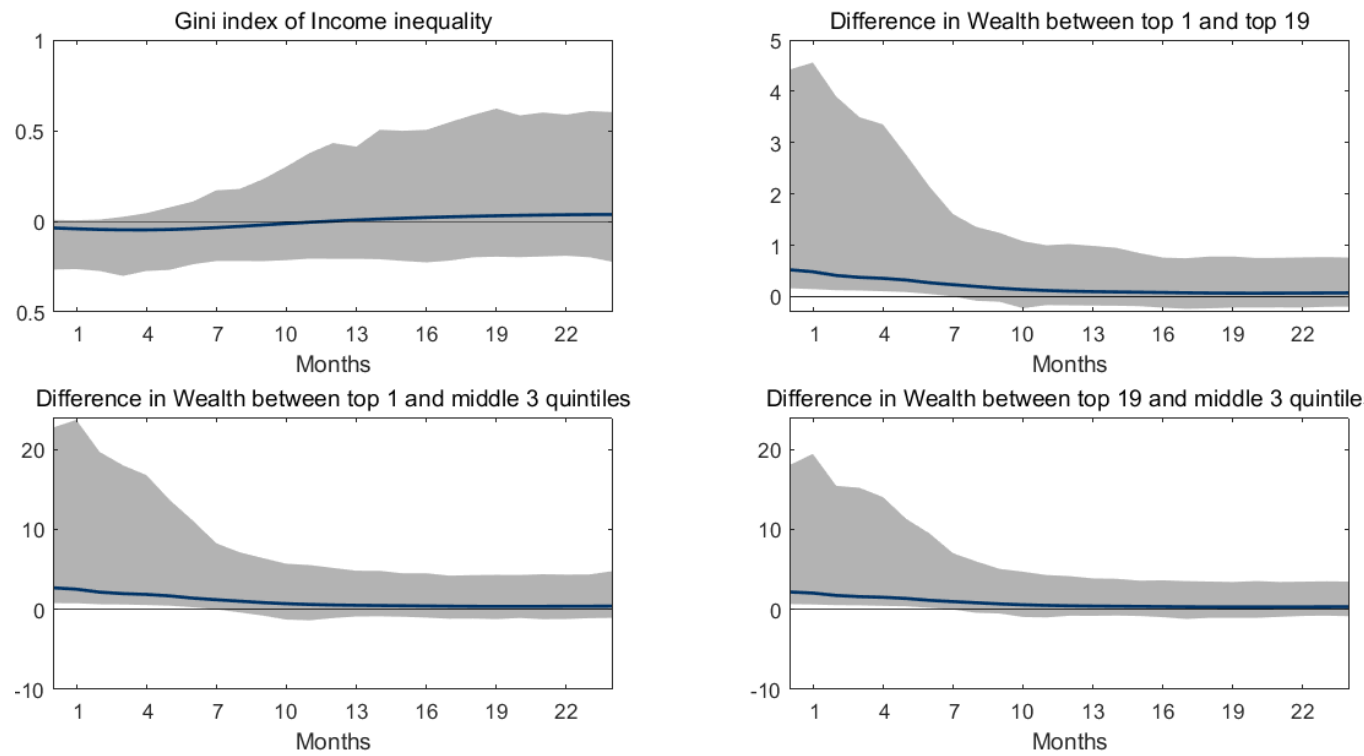

Note: IRFs to a 20 basis point decrease in the one-year government treasury bill for the direct measures of income and wealth inequality from the baseline. Sample: 1982M1:20012M12. Shaded regions represent 90\% posterior confidence bands. 
Figure D.14: Inequality transmission channels for the baseline after a LSAP monetary policy shock
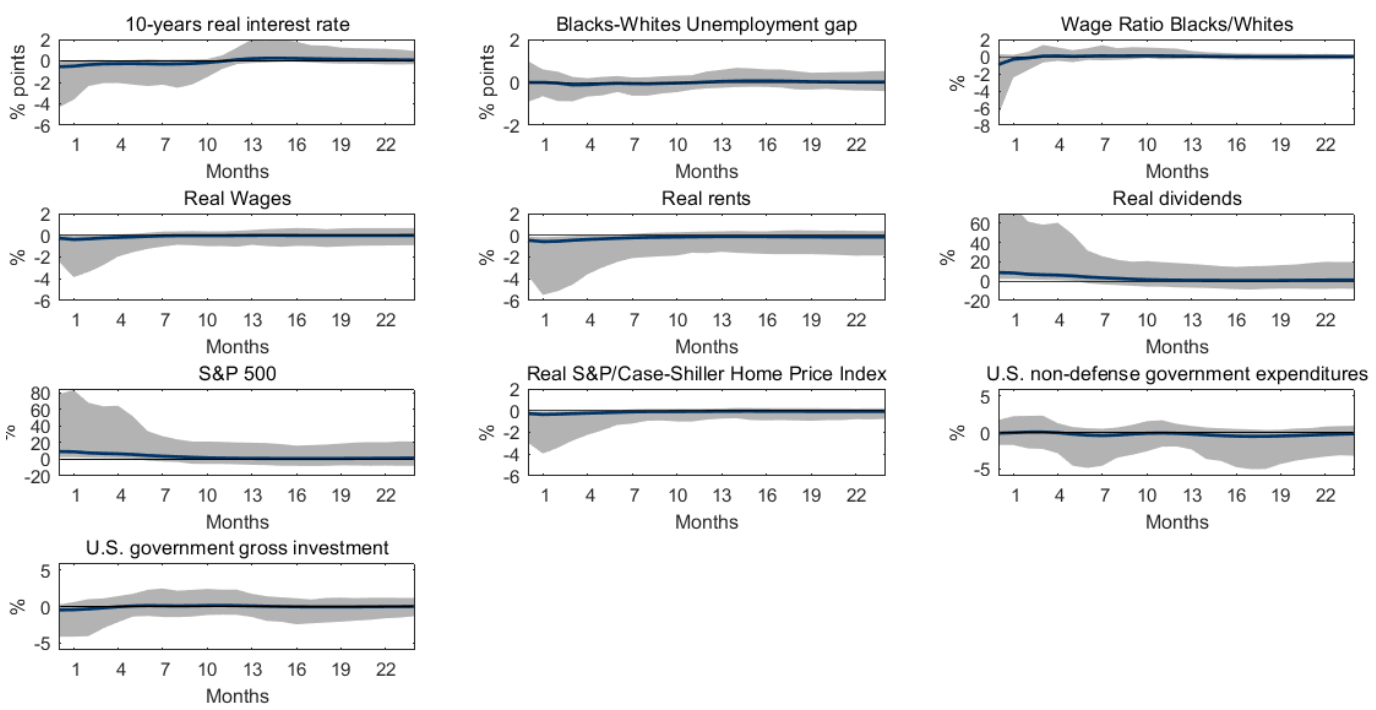

Note: IRFs to a 20 basis point decrease in the one-year government treasury bill for the monetary policy transmission channels from the baseline. Sample: 1982M1:2012M12. Shaded regions represent 90\% posterior confidence bands. 
Figure D.15: Inequality measures for the baseline under the SBC
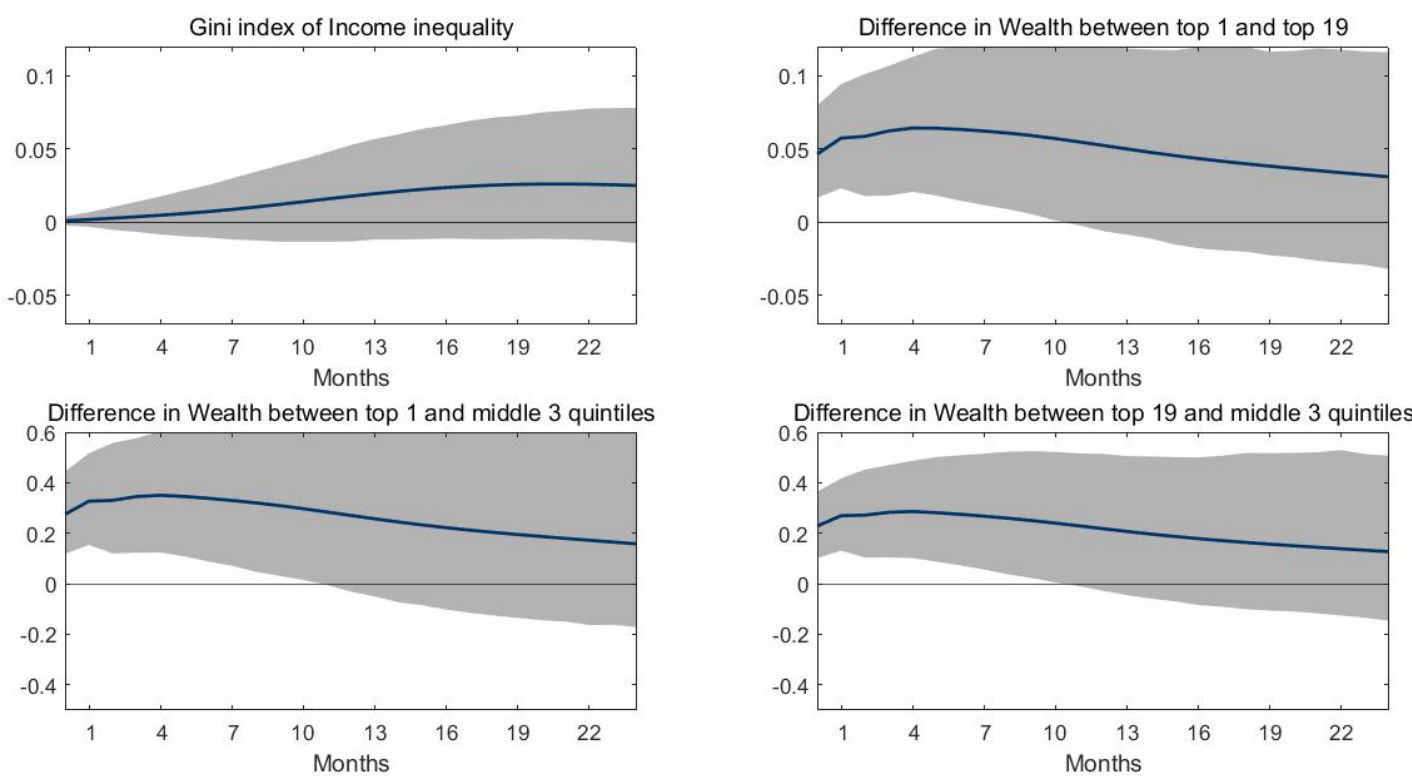

Note: IRFs to a 20 basis point decrease in the one-year government treasury bill for the direct measures of income and wealth inequality from the baseline.

Sample: 1982M1:2012M12. Shaded regions represent 90\% posterior confidence bands. 
Figure D.16: Inequality transmission channels for the baseline under the SBC
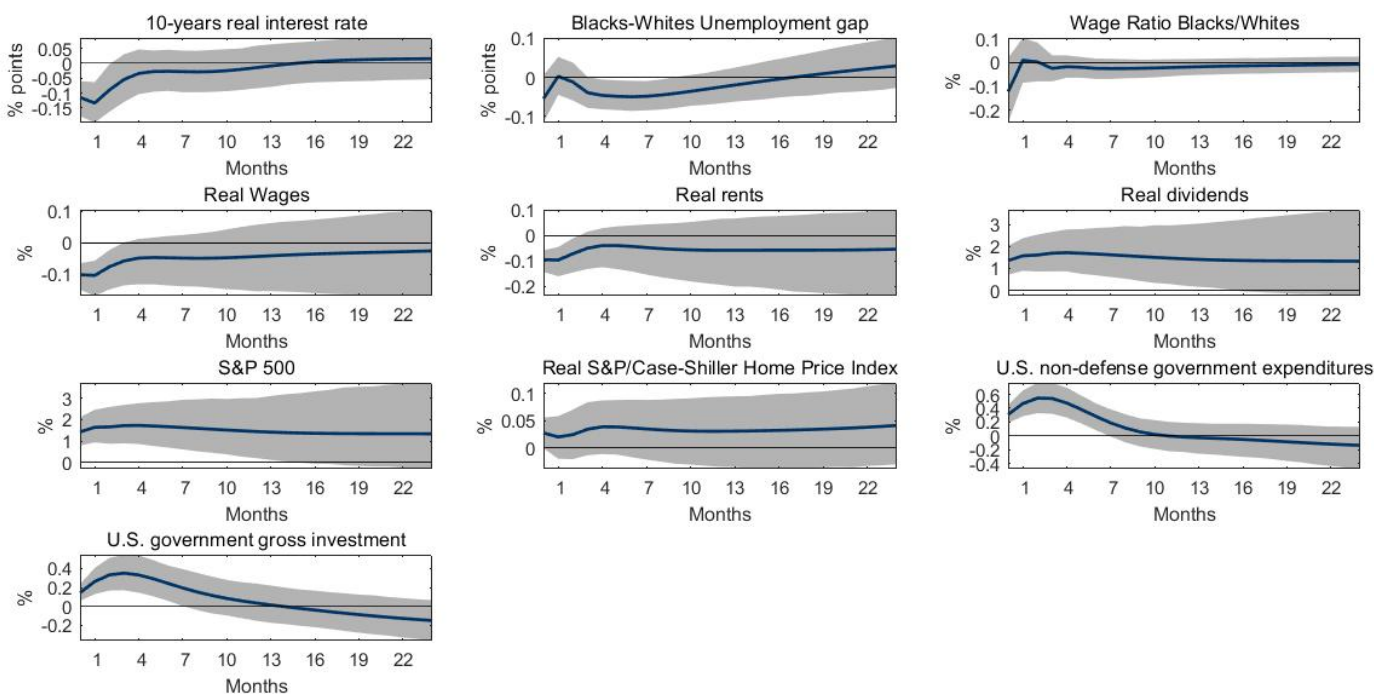

Note: IRFs to a 20 basis point decrease in the one-year government treasury bill for the monetary policy transmission channels from the baseline. Sample: 1982M1:2012M12. Shaded regions represent $90 \%$ posterior confidence bands. 
Figure D.17: Inequality measures for the baseline using BLP
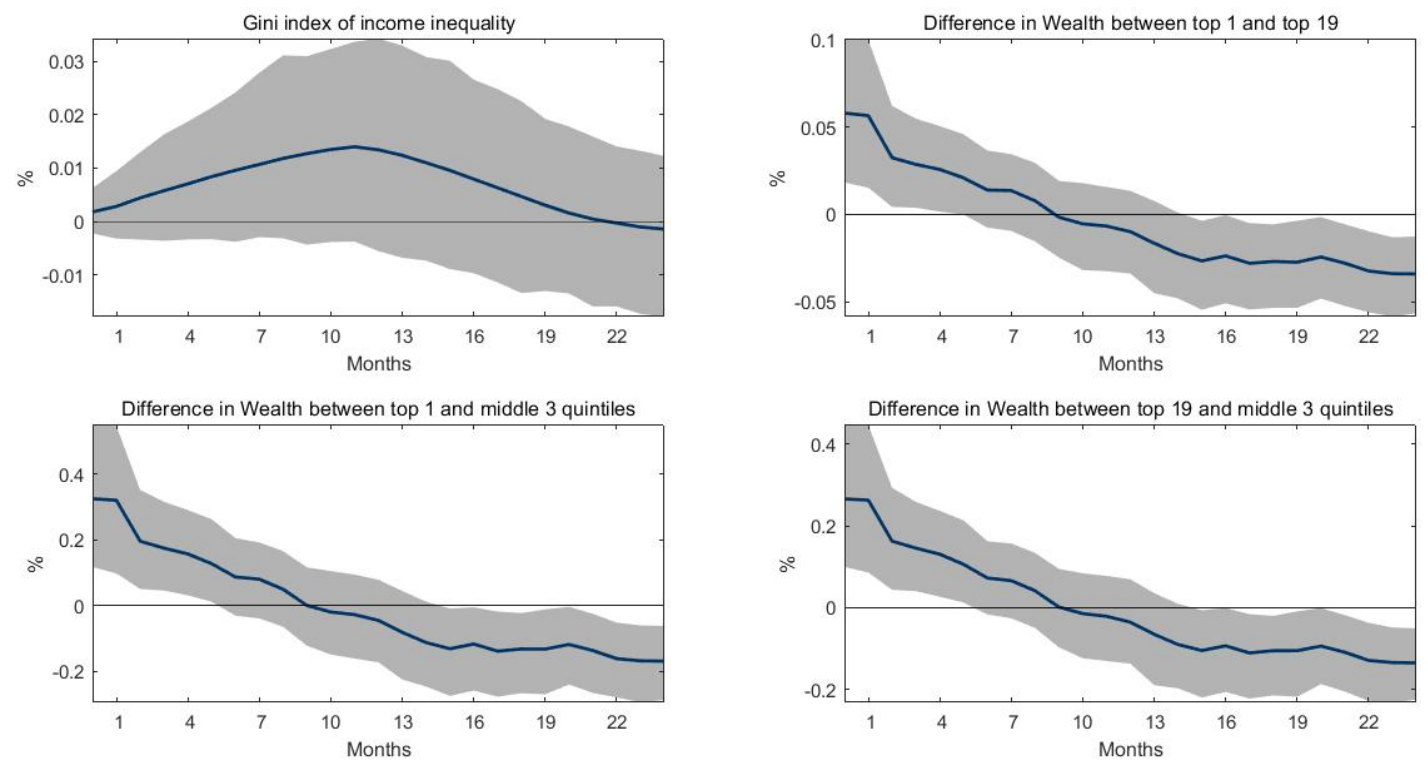

Note: IRFs to a 20 basis point decrease in the one-year government treasury bill for the direct measures of income and wealth inequality from the baseline estimated by the BLP methology. Sample: 1982M1:2012M12. Shaded regions represent $90 \%$ posterior confidence bands. 
Figure D.18: Inequality transmission channels for the baseline using BLP
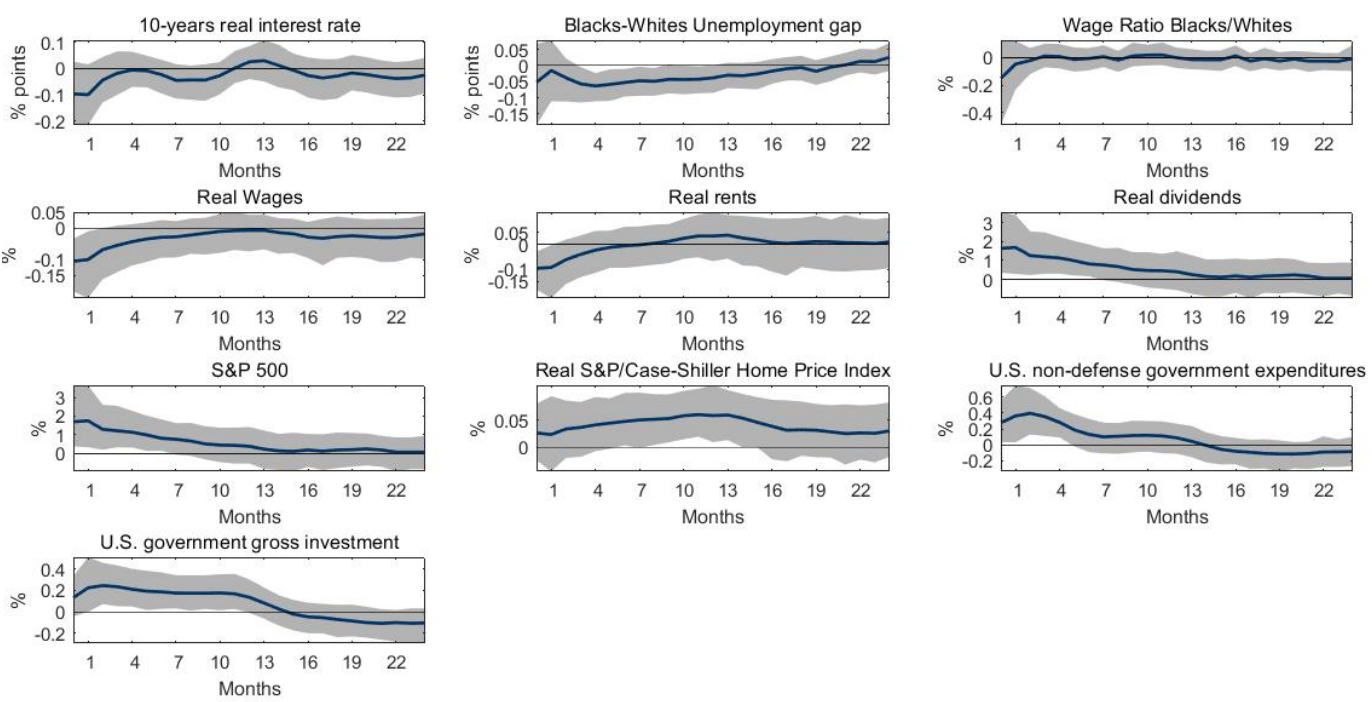

Note: IRFs to a 20 basis point decrease in the one-year government treasury bill for the monetary policy transmission channels from the baseline estimated by the BLP methology. Sample: 1982M1:2012M12. Shaded regions represent 90\% posterior confidence bands. 